\title{
The Use of Cellulose Nanofillers in Obtaining Polymer Nanocomposites: Properties, Processing, and Applications
}

\author{
Fernanda Abbate dos Santos*, Gisele C. V. Iulianelli, Maria Inês Bruno Tavares \\ Instituto de Macromoléculas Professora Eloisa Mano da Universidade Federal do Rio de Janeiro (IMA/UFRJ), \\ Centro de Tecnologia, Bloco J, Ilha do Fundão, Rio de Janeiro, Brazil \\ Email: ${ }^{*}$ fabbate@ima.ufrj.br
}

Received 21 March 2016; accepted 17 May 2016; published 20 May 2016

Copyright (C) 2016 by authors and Scientific Research Publishing Inc.

This work is licensed under the Creative Commons Attribution International License (CC BY). http://creativecommons.org/licenses/by/4.0/

c. (i) Open Access

\begin{abstract}
In recent years, several studies have been performed using nanocellulose as a component in polymeric nanocomposites. The interest in studying cellulose-based nanocomposite is due to the abundance, renewable nature, and outstanding mechanical properties of this nanoparticle. However, obtaining nanocomposites based on nanocellulose, with optimal properties, requires good nanoparticle dispersion in the polymeric matrix. The chemical compatibility between nanofiller and polymer plays a major role in both the dispersion of particles in the matrix and the adhesion between these phases. The aim of this review is to present the fundamental concepts about nanocellulose, such as its structural aspects, production methods and current trends in classification, and the main aspects about cellulose-based nanocomposites, including the progress that has been reached in relation to their compatibilization, production, final properties and potential applications.
\end{abstract}

\section{Keywords}

Cellulose, Nanocomposites, Processing, Properties

\section{Introduction}

The number of research studies on polymeric materials from renewable natural sources has been growing markedly in recent years [1]. Interest in these materials is directly related to an obligation to reduce society's dependence on materials obtained from fossil sources [2] [3]. In addition, these renewable materials also exhibit

"Corresponding author.

How to cite this paper: dos Santos, F.A., Iulianelli, G.C.V. and Tavares, M.I.B. (2016) The Use of Cellulose Nanofillers in Obtaining Polymer Nanocomposites: Properties, Processing, and Applications. Materials Sciences and Applications, 7, $257-294$. http://dx.doi.org/10.4236/msa.2016.75026 
properties such as biodegradability, biocompatibility, low toxicity, and low cost among others [4]. These properties provide a great potential for use in applications from plastic bags and packaging to biomedical fields, including bone plates, fixation screws or sutures. However, to replace petroleum-based thermoplastics, biopolymers need to have comparable properties and processing methods to those conventionally used. In order to improve their properties, many biopolymers have been used in the preparation of nanocomposites [1].

Similar to conventional composites, nanocomposites are composed of at least two components; one of them is the matrix or continuous phase, in which nanosized particles are dispersed. These nanosized particles or nanoparticles constitute the second phase, referred to as the dispersed phase. Polymer nanocomposites are a recent alternative to conventionally filled polymers. Due to the reduced size of dispersed phase and its good dispersion in the polymer matrix, these materials exhibit markedly improved properties when compared to the pure polymers or their traditional composites [5]. They also exhibit unique optical, electrical, and magnetic properties [6].

Biopolymers, such as chitin, starch, and cellulose, can be employed as reinforcement filler or as matrix in the production of nanocomposites [2]. Cellulose is one of the best natural materials to generate nanofillers for producing nanocomposites that are based on renewable raw material sources, because it is the most abundant biopolymer in nature and is available in a wide variety of resources, such as plants and microorganisms [7]-[11].

The nanofillers isolated from cellulose have been used as a reinforcing material in many natural and synthetic polymers [12]-[18]. The use of these nanofillers has proven effective due to the large surface area and the excellent mechanical properties presented by cellulose [19]. Furthermore, the addition of cellulose-based nanofillers promotes a better performance of the nanocomposite in relation to their barrier, thermal and mechanical properties among others. However, there are some challenges to overcome in relation to the use of cellulose-based nanofillers in polymers to produce nanocomposites in order to achieve good performance, including the efficient dispersion of particles in the matrix, the compatibility of nanoreinforcement in the matrix and the development of suitable methods for the processing of these materials.

\section{Cellulose}

Cellulose is a natural polymer classified as polysaccharide, which is most frequently found in the plant kingdom, comprising at least one third of the vegetable material in the world [20] and, it is present in materials such as wood, seeds and agricultural waste.

This biopolymer can be synthesized by bacteria, such as Acetobacter [21] and it is present in a highly crystalline form in the cell walls of algae such as Valonia and Microdicyon [22]. It is possible to find cellulose in the animal kingdom and the most studied source is the membrane of a marine animal referred as tunicate [23].

\subsection{Selecting a Template Cellulose Structure}

Cellulose is composed of large polymer chains with variable molecular weight and empirical formula $\left(\mathrm{C}_{6} \mathrm{H}_{10} \mathrm{O}_{5}\right)$ n. The degree of polymerization (DP) of cellulose, and consequently its molecular weight, depends on the cellulosic source, the processes and further treatments used in obtaining this biopolymer [24] [25]. The DP of cellulose can vary between 10,000 and 15,000 [26] [27]. Generally, the DP of cellulose profoundly influences the mechanical, solution, biological, and physiological properties of cellulose [28].

In relation to its molecular structure, cellulose is classified as a linear condensation polymer that is formed from connecting D-glucose units condensed through the $\beta$-1,4-glycosidic bonds [29]-[31]. The resulting repeat unit formed is called cellobiose (Figure 1).

Cellobiose presents six hydroxyl groups, which form intra- and intermolecular hydrogen bonds [32]. The hydrogen bonds between hydroxyl groups of adjacent glucosides units of the same cellulose molecule are intramolecular and are responsible for a certain rigidity of the unit chains [33]. The intramolecular hydrogen bonding formed between hydroxyl groups and oxygens of the adjoining ring molecules stabilizes the linkage and results in the linear configuration of the cellulose chain [27].

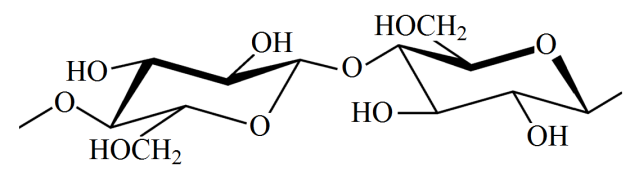

Figure 1. Cellobiose (repeat unit of cellulose polymeric chains). 
In cellulose, intramolecular bonds occur between hydroxyl groups of adjacent cellulose molecules [34]. Van der Waals forces additionally to these intermolecular hydrogen bonds are responsible to the occurrence of parallel stacking of multiple cellulose chains forming elementary fibrils that further aggregate into larger microfibrils (5 - $50 \mathrm{~nm}$ in diameter and several microns in length) [27].

In these microfibrils, the bundles of elongated molecules in which highly ordered crystalline regions alternates with less ordered regions (amorphous) [34].

The cellulose crystallinity degree varies according to factors such as the cellulose source and material processing [34]. For instance, the degree of crystallinity of cellulose obtained from cotton, bacteria, cotton, and Valonia algae is about, $40 \%, 75 \%$, and $93 \%$, respectively [35] [36]. Due to this crystalline structure, cellulose is insoluble in water and typical organic solvents and can only be dissolved if the intra- and intermolecular hydrogen bonds are effectively disrupted [37].

The structure of cellulose confers to their nanofillers properties such as large aspect ratio, compatibility with natural polymers, high values of strength and modulus as well other favorable physical properties associated with the high crystallinity of the chains. These properties have made the cellulose nanoparticles materials of great potential to being used as reinforcement in polymeric matrix to produce nanocomposites.

\subsection{Cellulose Sources}

\subsubsection{Vegetable Lignocellulosic Materials}

Lignocellulosic materials are heterogeneous complexes composed of carbohydrate polymers (cellulose and hemicellulose), and lignin [38]. There are many vegetable lignocellulosic materials that can be used to produce cellulose, such as wood, cotton, sugarcane, ramie, sisal, flax, wheat straw, among others.

Wood as a cellulose source material presents many advantages, being its abundance the most significant of them. Furthermore, an existing infrastructure is in place for harvesting, processing and handling, i.e., the pulp and paper, packaging and pharmaceutical industries [27]. Similarly, plants are also an attractive cellulose source primarily due to their abundance in nature and to a preexisting infrastructure in the textile industries for harvesting, retting/pulping, and product processing [27].

There are many pulping methods used to isolate cellulose from lignocellulosic sources. The first step of any of these methods consists of promoting the delignification of the raw material. Among the methods used to produce cellulose, the best known is the Kraft chemical process [39].

This pulping process involves cooking the raw material with a solution containing hydroxide and sodium sulfide at $160^{\circ} \mathrm{C}$ in a pressurized vessel called a digester [40]. The lignin component of the wood becomes progressively depolymerized, chemically substituted, and eventually solubilized. The lignin removal occurs mainly by cleavage reactions of $\alpha$-aryl ether and $\beta$-aryl ether linkages by hydroxide anions and hydrosulfide, which cleave the lignin macromolecules into smaller fragments that are soluble in aqueous and alkaline medium [40].

Large part of the lignin present in the lignocellulosic matrix is removed in the Kraft process, in which most of the cellulose is preserved [41]. To a lesser degree, Kraft pulping causes hydrolysis and solubilization of hemicellulose, further reducing the yield of the process.

Depending on the extent of the Kraft process, the resulting fibers can have lignin contents in the range of roughly $1 \%$ to $10 \%$ of the total dry mass, and the color can be generally described as brown or tan, depending on the yield [42]. As the resulting cellulose pulps generally have a dark color, it becomes necessary to use a bleaching process to achieve greater levels of brightness, without the loss of either the physical or mechanical properties of the cellulose pulp [43].

Bleaching is a chemical treatment that is completed in several stages, and is applied in the chemical or mechanical pulp in order to decolorize or remove the non-cellulosic coloring material existing in the mass, therefore increasing the whiteness of the final product [44]. This process is carried out through either oxidizing agents, such as chlorine gas, chlorine dioxide, sodium hypochlorite, hydrogen peroxide, and oxygen, or through reducing agents, such as zinc hydrosulfite [42] [45]. Between bleaching treatments, a strong alkali, usually sodium hydroxide, is used to extract the dissolved lignin from the surface of the fibers [45]. The bleaching agents and the sequence in which they are used depend upon a number of factors, including the relative cost of the bleaching chemicals, the type and condition of the pulp, as well as agents prohibited in environmental guidelines and regulations.

Oxygen delignification is becoming increasingly popular as an initial stage of bleaching, due to the fact that 
the bleach effluent can be included in the Kraft chemical recovery cycle, therefore allowing any dissolved lignin or carbohydrate byproducts to be incinerated, with the recovery of energy [42]. Chlorine dioxide is another, even more powerful oxidizing agent, and is a more highly selective bleaching agent, capable of solubilizing the residual lignin [42]. However, the solubilized material from the $\mathrm{ClO}_{2}$ stage cannot be sent to the Kraft recovery boiler [42].

Peracids are also strong oxidizing species, and their use is being largely studied in the delignification and cellulose pulp bleaching. According to Brasileiro, Colodette and Piló-Veloso [46], peroxides, especially peracetic and permonosulphuric acid, are currently considered great substitutes for chlorinated reagents. These acids are highly oxidative species and promote the production of cellulose pulps with higher strength and higher levels of delignification, thus enabling lower reversions of whiteness after bleaching and decreasing the degradation of cellulose [47]. Furthermore, peroxyacids have been successfully employed in high throughput delignification-bleaching sequences in conjunction with alkali treatments, especially $\mathrm{NaOH}, \mathrm{KOH}$, or $\mathrm{NH}_{4} \mathrm{OH}$ [48].

Another method of obtaining cellulose pulp is the sulfite process, which is the second major chemical pulping process currently in commercial use. In this method, lignin dissolution is carried out by sulfonation with an aqueous solution of sulfur dioxide and calcium, sodium, magnesium, or ammonium bisulfite, and cooked at high temperature and pressure in a digester [45].

Sulfite processes has poor ability to dissolve extractives, thus these pulping methods are suitable only for species of wood with low extractive contents [49]. Substances such as tannins, polyphenols, pigments, and resins, when in high content, can interfere with the sulfite pulping process [45] [50]. Although calcium is the cheapest sulfite base available, it is seldom used because it forms insoluble compounds that cannot be reclaimed economically [45]. On the other hand, magnesium- and sodium-based chemicals are recoverable, while ammonium-based chemicals are less expensive and can be burned without harmful environmental effects [45]. Consequently, they are the most frequently used [45].

The pulping processes involving sulfur-based compounds, such as Kraft and sulfite methods, have the disadvantage of emitting unpleasant odor gases. As a result, the quest to reduce atmospheric emissions of sulfur gases has made an important goal for many industrial plants [51]. Some researchers have focused on developing and improving established pulping and bleaching processes, as well as finding new pulping technologies.

The influence on the use of anthraquinone in the pulping of Eucalyptus saligna wood chips was evaluated by Jerônimo, Foelkel, and Frizzo [51]. This study presented the objective of reducing the emission of sulfur compounds in the Kraft process by reducing the sulfidity. An increase in sulfidity corresponds to an increased amount of both sulfide and hydrosulfide ions in the liquor and, consequently, an increase in the formation of malodorous compounds. In general, the addition of anthraquinone improved the delignification, therefore enabling the reduction of sulfidity. The researchers concluded that this process can be used instead of the conventional Kraft process without causing damage during the pulping process.

El-Ghany [52] studied the prehydrolysis soda ethanol anthraquinone pulping of cotton linters to produce cellulose. The results showed that a more stabilized cellulose against alkaline degradation was obtained as compared to that obtained by using the prehydrolysis soda pulping.

Castellan and colleagues [53] conducted a pulping process of sugarcane bagasse with peroxyformic acid, followed by bleaching in two stages, combining photocatalysis and photosensitization. The first stage consisted of an irradiation of the pulp under alkaline $\mathrm{pH}$ in an aqueous suspension in the presence of $\mathrm{TiO}_{2}$ with tungsten or mercury lamps. The second photobleaching stage performed with hydrogen peroxide completed the delignification and the brightness gain, completely removing the sensitizer from the pulp.

Another pulping process of sugarcane bagasse was presented by Sun et al. [54] using sequential treatments of $\mathrm{NaOH}$ and $\mathrm{H}_{2} \mathrm{O}_{2}$ in an alkaline medium and treated with $80 \%$ acetic acid $/ 70 \%$ nitric acid $(10: 1 \mathrm{v} / \mathrm{v})$ at high temperature. According to these researchers, this method may be considered an improvement on others used for the isolation of high purity cellulose that is relatively free of contaminated lignin and hemicelluloses. However, this method resulted in some degradation and partial acetylation of the cellulose structure.

\subsubsection{Bacterial Cellulose}

Among the bacteria, one of the most studied type of these microorganisms that produces cellulose is generally called Acetobacter. These microorganisms can procure glucose, sugar, glycerol or other organic substrates and convert them into pure cellulose [55].

Under special culturing conditions the bacteria secrete cellulose microfibrils, producing a thick gel composed 
of cellulose microfibrils and approximately 97\% water, called pellicle, on the surface of the liquid medium [56] [57]. The bacterial cellulose can be produced in both synthetic and non-synthetic medium through oxidative fermentation [58]. Generally, the bacteria actively fermented at $\mathrm{pH} 3-7$ and $25^{\circ} \mathrm{C}-30^{\circ} \mathrm{C}$, using saccharides as carbon source [59].

The biosynthesis of bacterial cellulose occurs in culture solutions, in a bioreactor, in which bacteria secrete cellulose microfibrils, producing an interwoven web of fibrils that is a hydrogel [56] [57] [60] [61]. These hydrogels are composed of a network of entangled cellulose microfibrils formed due to the random movement of the bacteria [61].

After the biosynthesis, the produced cellulose pellicles are washed by boiling in a low concentration (2\%) $\mathrm{NaOH}$ bath for several hours, after which it is rinsed under running water for several days in order to remove the bacteria. Posteriorly, the water is removed either by evaporation or a combination of pressing and evaporation collapses the gel-network and produces a dense film $\left(1.0 \mathrm{~g} \cdot \mathrm{cm}^{3}\right)$. The resulting films have a through-film thickness made up of many parallel stackings of thin cellulose sheets, or layers, each consisting of a dense microfibril network [62]-[64].

The cellulose microfibril morphology and the network configuration within the pellicle can be changed by variation in culture conditions such as bacteria type [56], carbon source [65] nutrients [57], temperature [57], $\mathrm{pH}$ [57] and agitation [56] [66]. The changes in microfibril morphology and network configuration make possible alter the properties of the pellicle and the engineered bacterial cellulose materials [66].

In relation to agitation conditions, fermentation of bacterial cellulose production can be conducted in either static or stirred conditions. Different forms of cellulose are produced under these conditions. Three-dimensional interconnected reticular pellicle was reported under static condition while stirred condition produced irregular shape sphere-like cellulose particle [67]. The sphere-like cellulose particle has lower crystallinity, mechanical strength and degree of polymerization compared to pellicle from static culture [68].

Carbon source can affect the bacterial cellulose production. In general, glucose has been used as a carbon source for cellulose production by Acetobacter xylinum. It has been reported, however, that cellulose was also synthesized from other carbon sources, such monosaccharides, oligosaccharides, starch, alcohol and organic acids [69]-[73]. Fructose and glycerol gave almost the same cellulose yield as glucose [74]. However, galactose and xylose generated smaller yields, mostly because of slower growth rates [75]. The microfibrils obtained from xylose are also less regular than those obtained from glucose.

The usage of glucose as carbon source is associated with the formation of gluconic acid as by-product, which decreases the $\mathrm{pH}$ of the culture and negatively affects the quantity of bacterial cellulose production [58]. The amount of cellulose from D-arabitol by Gluconacetobacter was more than 6 times as much as that from D-glucose in the work of Oikawa, Morino and Ameyama [59]. In D-arabitol medium, the final $\mathrm{pH}$ did not decrease and D-gluconic acid was not detected, this seems to be one of the reasons for high productivity of cellulose from D-arabitol. On the other hand, the presence of antioxidant and polyphenolic compounds manages to inhibit the gluconic acid formation [76].

Medium supplementation with some nutrients can also affect the production of bacterial cellulose. For instance, nitrogen and phosphorus sources have been shown to increase bacterial cellulose production [77].

The possibility to change the culture conditions consists in an advantage of bacterial derived cellulose microfibrils, because this can alter cellulose properties such microfibril formation and crystallization [78] [79].

In addition, when cellulose is synthesized by an Acetobacter strain, the produced biopolymer is devoid of other contaminating polysaccharides and its isolation and purification are relatively simple, not requiring energy or chemical intensive processes [80]. Moreover, environmental problems due to byproducts of wood pulping have been given an added impetus to study unexplored sources of cellulose [81].

\subsubsection{Tunicate Cellulose}

Tunicates are the only animals known to perform cellulose biosynthesis. The current hypothesis about the synthesis of cellulose by tunicates is that a horizontally acquired cellulose synthase gene of bacterial origin might have contributed to the establishment of this unique characteristic [82]. Tunicates are a family of sea animals that have a mantle or tunic, which is integumentary tissue consisting of cellulose microfibrils embedded in a protein matrix [27] [83]. This mantle is used as a source of cellulose microfibrils in their mature phase. The tunic contains approximately $60 \%$ cellulose, $27 \%$ nitrogen-containing components and, approximately $90 \%$ water in the fresh condition [84]. 
The cellulose in the tunic is aggregated in the form of microfibrils similar to those of plant cellulose [85]. Cellulose microfibrils in tunicates are deposited in a multilayered texture with a bundled structure parallel to the epidermis [86]. There are many species of tunicates, and the cellulose microfibril structure and properties are expected to be comparable between these species, but there may be small differences in the cellulose microfibril formation process which may be reflected in the resulting microfibril structure [87].

Many studies have been conducted to isolate tunicate cellulose using different methods. All of them involve as first step the separation of cellulose mantles from the rest of the organs.

The tratment of tunicate mantles with $\mathrm{KOH}$ solution at an elevated temperature have been used to isolate cellulose [88]-[90].

The isolation of tunicate cellulose was described by Zhang et al. [90]. In this method the cellulose mantles separated from the rest of the organs were cut into small pieces and soaked in a $10 \mathrm{wt} \% \mathrm{KOH}$ solution for $24 \mathrm{~h}$ followed by washing and then bleached at $60^{\circ} \mathrm{C}$ with $30 \mathrm{~mL}$ of $\mathrm{NaClO}$ in $1 \mathrm{~L}$ of acetic buffer for $24 \mathrm{~h}$, and the resultant white mantles were washed till neutrality. After this procedure, the obtained material was hydrolyzed with sulfuric acid in order to obtain cellulose nanocrystals.

Nakashima, Sugiyama and Satoh [82] obtained the cellulose from adult specimens of the tunicate Ciona intestinalis. After the surgical removal of the tunic, the samples were drying at $60^{\circ} \mathrm{C}$ and then, treated with potassium hydroxide. After neutralization with acetic acid, the samples were bleached with $\mathrm{NaClO}_{2}$. After being washed with distilled water, the samples were treated with acetic acid/nitric acid aqueous solution at $95^{\circ} \mathrm{C}$ for 30 min, washed with distilled water again, and freeze-dried to produce chemically purified cellulose.

Similar methods were described by many authors [91]-[98]. These authors also used a combined treatment with $\mathrm{NaOH} / \mathrm{KOH}$ solution at an elevated temperature, followed by treatment with a $\mathrm{NaClO}_{2}$ solution.

Cellulose microfibrils from tunicate were isolated from an enzymatic process by Wardrop [99]. The method was carried out by using pepsin as a proteinase for 16 hours, followed by cellulase for 16 hours.

The cellulose produced from tunicates has taken special interest of these years, due to its preparation, which requires only mild chemical and enzymatic treatment. [85]. In addition, tunicates have the potential to produce nearly defect-free cellulosic nanocrystals with relative purity [100]. Due to these characteristics, many studies have evaluated the isolation and use of tunicate cellulose in a variety of ways [101]-[111].

\subsubsection{Algae Cellulose}

Algae are phototrophs that occur in freshwater and marine environments. Algae can vary from small unicellular microalgae, such as cyanobacteria and diatoms, to large multicellular macroalgae, such as giant kelp [112]. They live principally on coastal rocks and shallow seas [113].

Several species of algae produce cellulose microfibrils within the cell wall. Cellulose is composed of xylem and manna found in green algae (Cladophora and Valonia), brown (Phaeophyta) and red algae (Rhodophyta) and serves as the structure of the cell wall of polysaccharides in algae [114].

In land plants, cellulose is the only skeletal polysaccharide, which mostly provides the tensile strength of the cell wall [115]. In marine algae, cellulose is present in a smaller and more variable proportion than in higher plants. In both red and brown algae, the cellulose content is rather low [116]. Most green algae have a cellulosic cell wall, with high cellulose content, ranging up to $70 \%$ of the dry weight [117]. The cellulose content in the cell walls of green algae is of the same order of magnitude as that of wood [118].

There are considerable differences among the cellulose microfibril structures produced by many algae species. These differences are caused by variations in the biosynthesis process of the cellulose microfibrils [27].

In some green algae, native cellulose is the major component of their cell walls. These algae belong those of the Cladophorales and Siphonocladales orders [119]. The cellulose derived from these groups of green algae, for example, from Valoniaor Cladophora, is featured with an exceptionally high degree of crystallinity [120][122] and extensive surface area [121]. On the other hand, there are some green algae, such as Spongomorpha, in which the cell walls contain a large quantity of mercerized like cellulose, which is presumably a derivative of native cellulose [119]. This cellulose has a low degree of crystallinity, and the chains are randomly oriented.

The natural reason for the presence of highly crystalline cellulose microfibrils in the cell walls of many marine green algae is not clear. It has been suggested that strong microfibrils may be needed to maintain the turgor (i.e., osmotic pressure inside cells) in an environment that features fluctuating salinity [123].

Cellulose microfibril from green algae have been obtained and studied by many researchers. Some of the most frequently studied species used in these researches have been Micrasterias denticulate [124] [125], Micrasterias 
rotate [124], Valonia [126]-[129], Caldophora [129] and Boergesenia [129].

The isolation of cellulose from algae requires some steps, which includes a pretreatment of algal cellulose sources. These pretreatments typically involve culturing methods, and then purifying steps for removal of algal wall matrix material [27]. Cellulose nanoparticles can be extracted from the cell wall of algae by acid hydrolysis and mechanical refining.

A procedure for obtaining cellulose from Cladophora green algae and Algiflor brown algae was described by Mihranyan et al. [130]. In this method, samples of each algae type were bleached with $\mathrm{NaClO}_{2}$ in acetic buffer. The mixture was diluted and stored in a water-bath for $3 \mathrm{~h}$ at $60^{\circ} \mathrm{C}$. Then, the product was washed until neutrality. A solution of $\mathrm{NaOH}$ was added to the remainder, and the resultant product was stored at $60^{\circ} \mathrm{C}$ in a water-bath overnight. The resultant pulp was washed till neutrality, filtered, and dried at room temperature. Dry, purified algae were ground prior to acidic hydrolysis. After this process, the remainder was washed till neutrality, filtered and spray-dried. This method to obtain algae cellulose was also employed by Mihranyana Edsmana and Strømme [131] in their investigation of the rheological properties of cellulose hydrogels prepared from cellulose powder of Cladophora algae, and by Gelin et al. [132] in their work about electrochemical properties of a composite based on polypyrrole and cellulose from Cladophora algae.

Cellulose was isolated from Enteromorpha green algae by Jmel et al. [133] in order to investigate its physical-chemical properties and enzymatic functionalization. In this method, extractives and lipids were first of all eliminated from the dried ground algae by Soxhlet extraction using ethanol as solvent. Ulvan, a sulfated polysaccharide, was then extracted by adding distilled water containing ammonium oxalate to the defatted algae. The mix was then heated for one hour between $90^{\circ} \mathrm{C}$ and $100^{\circ} \mathrm{C}$. The algae was washed and then bleached in a mix of acetic acid and $\mathrm{NaClO}_{2}$. In the final step of the extraction, algae were treated with $\mathrm{NaOH}$. The insoluble fraction was then washed until neutrality and dried. The obtained powder was then treated with hydrochloric acid. The extracted cellulose was washed until neutrality and finally dried.

\subsection{Cellulose Particles Type}

In the literature, there is a variety of terms used in reference to cellulose particles. Occasionally, the same term is used to designate different materials, and this can cause uncertainty with respect to the classification of the cellulose particle. This is due to the fact there is not yet a nomenclature standard for these materials. In this review, the current trends in cellulose particle terminology and classification are discussed.

Cellulose particles can be differentiated from one another based upon size, aspect ratio, morphology, crystallinity, crystal structure, and properties. These characteristics are a consequence of the cellulose source and the particle extraction methods used.

The principal terms used to describe cellulose-based particles are cellulose microcrystalline (MCC), microfibrillated cellulose (MFC), nanofibrillated cellulose (NFC), cellulose nanocrystals (CNC), bacterial cellulose (BC), and algae cellulose (AC).

The term MCC is used to refer to a highly crystalline structure composed of bundles of multi-sized cellulose microfibril aggregates that are strongly hydrogen bonded to one another [42]. MCC is typically derived by sulfuric acid treatment of bleached kraft wood fibers, resulting in partial depolymerization of their amorphous regions. The acid treatment is followed by a series of washing and drying steps. This process produces a fine powder with particle sizes ranging between $10-50 \mu \mathrm{m}$ in diameter [27]. MCC is a commercially available material used for pharmaceutical and food industry applications [27] [42]. In recent years, this material has also been utilized as reinforcement filler in polymer composites. Figure 2 shows a scanning electron microscope (SEM) image of MCC.

MFC is a material consisting of particles that contain multiple elementary fibrils with an extremely high surface area, a high aspect ratio (10 - $100 \mathrm{~nm}$ wide and $0.5-10 \mathrm{~mm}$ in length), and segregated amorphous and crystalline regions [27] [134]-[136]. MFC is produced from highly purified wood and plant fiber pulp by using mechanical process using high shear forces. MFCs have been utilized as thickening agents in the food and cosmetics industries.

Several other terminologies have been used for many authors to designate this cellulose particle type. Some of the most common names found are nanocellulose, microfibrillar cellulose, microfibrillized cellulose, nanofibrillated cellulose, nanofibrillar cellulose, nanoscale fibrillar cellulose and cellulosic fibrillary fines [27] [42] [137][141]. 


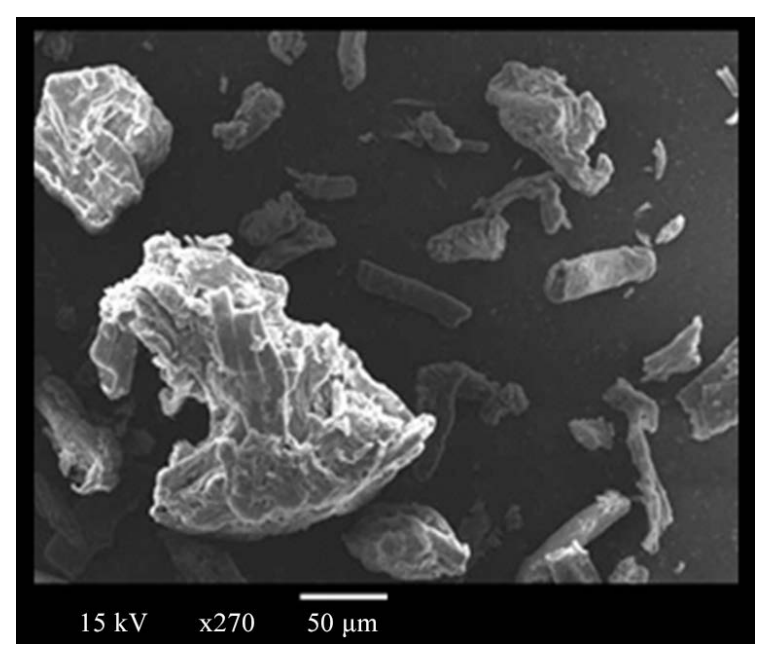

Figure 2. SEM photomicrograph of a sample of MCC.

NFC particles are finer cellulose fibrils produced when specific techniques to facilitate fibrillation are incorporated in the mechanical refining of cellulosic sources such as wood and plant fiber. NFC is a material that presents high aspect ratio (4 - $20 \mathrm{~nm}$ wide, $500-2000 \mathrm{~nm}$ in length), and contains both amorphous and crystalline regions [27]. NFC particles are similar to those of MFC. The difference between NFC and MFC is based on the fibrillation process that produces finer particle diameters. In the literature, there may some confusion between MFC and NFC terminology, which are sometimes used interchangeably [27].

CNCs are rod or whisker shaped particles seen in the crystalline regions of the cellulose fibrils produced by acid hydrolysis of wood fibers, microcrystalline cellulose and microfibrillated cellulose [142]-[144]. CNCs are highly crystalline particles with high aspect ratios (3 - $5 \mathrm{~nm}$ wide, $50-500 \mathrm{~nm}$ in length). These nanoparticles can also be produced by acid hydrolysis of tunicates [27] [145]. The advantage of CNCs derived from this source is that they are highly crystalline, and have the highest aspect ratio of any cellulose nanofiber. The ribbon-shaped CNCs from tunicates have typical aspect ratios between 70 and 100, and crystallinities ranging from $85 \%$ to $100 \%$. Cellulose nanocrystals have been also called whiskers [3] [11] [103] [146]-[150], rod-like cellulose microcrystals [151], nanowires [106] [152] and nanowhiskers [153]-[156].

Cellulose is also produced by several kinds of bacteria belonging to the genera Acetobacter, Agrobacterium, Alcaligenes, Pseudomonas, Rhizobium, and Sarcina [157]. BC is secreted extracellularly as a ribbon-shaped fibril less than $100 \mathrm{~nm}$ in width, which is comprised of much finer $2-4 \mathrm{~nm}$ nanofibrils [63] [158]. This material is produced in the form of a cellulose membrane with high purity. In contrast to cellulose isolated from plant-based sources, BC does not require any secondary chemical treatments to remove polymers such as lignin or hemicelluloses, as is the case for cellulose isolated from lignocellulosic sources [159] [160].

AC particles are comprised of microfibrils. The resulting microfibrils extracted from bacteria are microns in length and have large aspect ratios (greater than 40). When algae-derived cellulose is subjected to acid hydrolysis, the resulting nanocellulose is highly crystalline and similar to the nanocrystals obtained from wood sources. Although AC does not have the same rod-like appearance, the nanofibrils are approximately $20 \mathrm{~nm}$ wide and comparable in length $(>1 \mu \mathrm{m})$ to those of wood-based cellulose [43] [161] [162].

\subsection{Isolation of Cellulose Nanoparticles}

There are several approaches to isolate cellulose nanoparticles, including mechanical treatment [42] [137] [163][166], acid hydrolysis [18] [42] [137] [161] [167]-[169], and enzymatic hydrolysis [42] [137] [170] [171]. These methods can be used separately or in combination to obtain the desired particle morphology.

\subsubsection{Acid Hydrolysis}

The main processes for isolating cellulose nanofillers are chemical, and consist of using strong acids to promote a hydrolysis of the amorphous regions of cellulose [7] [29].

In this process, the amorphous regions are preferentially hydrolyzed, whereas the crystalline regions remain 
intact under the acid attack. This behavior occurs due a higher resistance to acid attack in the crystalline regions than those in the amorphous regions. Thus, the amorphous regions are first hydrolyzed [172] [173]. The differences in the kinetics of hydrolysis between the amorphous and crystalline regions produce a material with a high degree of crystallinity [173]. Acid hydrolyses of cellulose induces a rapid decrease in its degree of polymerization, and consequently leads to the production of nanosized particles through a reduction in the cellulose chains size. The resulting nanoparticles produced are called whiskers or cellulose nanocrystals.

Acid hydrolysis has been used to extract the crystalline particles from a variety of cellulose sources, such as wood, tunicate, algae, bacteria, and from microcrystalline cellulose. Many researchers [1] [3] [18] [167] [174][179] have isolated nanocrystals from the commercial MCC. The obtaining of nanocrystals from lignocellulosic sources requires a series of treatments, which are dispensed when commercial MCC is used as source to produce the cellulose nanoparticles.

The isolation of cellulose from lignocellulosic sources, including wood, sugarcane, coconut, etc., involves many processes. The lignin and hemicellulose are selectively removed from the fiber by thermal, chemical, physical, and biological methods, or by a combination of any of these methods, depending on the required degree of separation and the purpose for which they are intended [46]. When using MCC, the process of obtaining nanocrystals begins with hydrolysis, followed by final steps for isolating the nanofillers.

In this process, the cellulosic source selected to produce the nanoparticles is mixed into deionized water with a given concentration of acid, for example sulfuric or hydrochloric acid are generally used. After the addition of the acid, the resulting mixture is subjected to strictly controlled conditions of temperature, agitation, and time. After the reaction, the generated suspension containing the cellulose nanocrystals undergoes a series of separation steps, including centrifugation or filtration, and washing or rinsing steps. The last washing step is conducted using a dialysis against deionized water to remove the remaining acid and neutralized salts. Ultrasonic treatments can be used to facilitate the dispersion of $\mathrm{CNC}$ in the suspension. To obtain powdered CNC, the suspension can be freeze-dried after the dialysis procedure.

Sulfuric acid in a concentration of 64 to $65 \mathrm{wt} \%$ has been used in most studies for the isolation of cellulose whiskers [18] [108] [143] [174] [175] [178]-[182]. Acidic hydrolysis using hydrochloric acid is less common compared to hydrolysis with sulfuric acid, but has also been used in some studies [167] [183] [184]. The temperature can range from room temperature to $70^{\circ} \mathrm{C}$, and the reaction time can vary from 30 minutes to 8 hours, depending on the temperature used in the reaction [185].

When submitted to acid hydrolysis, the cellulose fibers yield stable aqueous suspensions of nanocrystals because of the presence of negative charges on the surface of produced material during the hydrolysis process. Stable suspension can be also formed when cellulose nanocrystals are dispersed in organic medium (Figure 3).

\subsubsection{Enzymatic Hydrolysis}

Cellulose nanocrystals may also be obtained through enzymatic hydrolysis, which is carried out using cellulases [42]. Similar to acid hydrolysis, the treatment used to obtain the nanofiller is based on the enzymatic attack of amorphous regions of the cellulose substrate, while maintaining the crystalline regions [42].

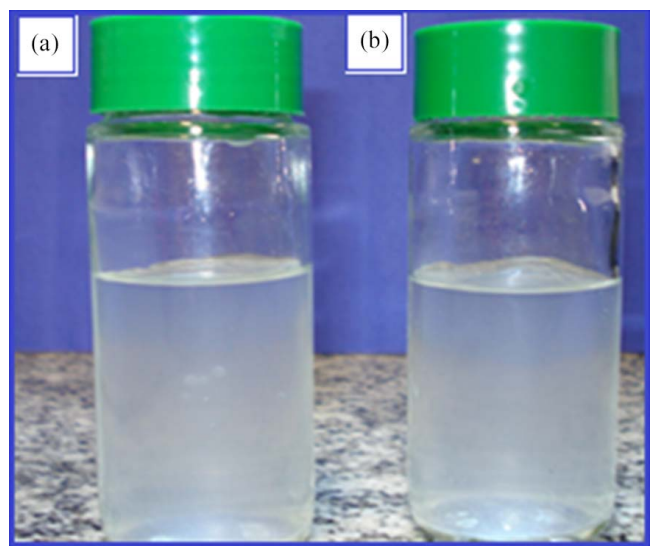

Figure 3. Stable suspensions of $\mathrm{CNC}$ in aqueous medium (a) and in chloroform (b). 
Henriksson et al. [186] employed an enzymatic treatment to isolate cellulose nanoparticles, where they treated wood-bleached pulp with the endoglucanase enzyme. They reported that such treatment made it easier to separate the material into micro-fibrillated cellulose (MFC) under mechanical shearing when compared to the isolation of the nanofibers obtained by acid hydrolysis. Further, Paakko et al. [187] found that by using a combination of enzymatic hydrolysis and mechanical shearing, it was possible to liberate the relatively long, rod-like cellulose units. Additionally, Janardhnan and Sain [188] studied the effect of enzymatic treatment of wood fibers with the purpose to isolating micro-fibrillated cellulose. In this study, it was observed that enzymatic hydrolysis made it possible to achieve smaller particles after refining through high shear than those that were not subjected to enzyme treatment.

Tang et al. [189] have used combined acid hydrolysis, enzymatic hydrolysis and sonication processes to produce CNC from old corrugated container pulp fiber. Results showed that the enzymatic treatment led to the increased crystallinity and thermal stability of $\mathrm{CNC}$ and was effective in enhancing the $\mathrm{CNC}$ yield after phosphoric acid hydrolysis. In the absence of enzymatic treatment, the CNC yield was $13.3 \%$; while the enzymatic treatment for 1, 12, 24 and $36 \mathrm{~h}$ made the $\mathrm{CNC}$ yield increased by $17.33 \%, 21.12 \%, 23.47 \%$ and $23.98 \%$, respectively, which, according to the authors, would greatly facilitate the economics of the industrial CNC production.

Recently, a novel approach to study of enzymatic activity of cellulases was used by Turon, Rojas and Deinhammer [190]. The researchers monitored the cellulose-cellulase interactions using a quartz crystal microbalance. Real-time measurements of the coupled contributions of enzyme binding and hydrolytic reactions were fitted to a kinetic model, which described the cellulase activities. This work demonstrated the remarkable difference in the time required to hydrolyze amorphous and crystalline films of cellulose.

According to Ahola et al. [191], a cost-effective conversion of cellulose via enzymatic fermentation requires detailed knowledge of the surface chemistry of the available forms of cellulose and the specific interactions between the enzymes and these substrates.

\subsubsection{Mechanical treatment}

Mechanical processes, such as high-pressure homogenization [163] [192] [193], microfluidization [193]-[195], cryocrushing [193] [196]-[198], high-intensity ultrasonic treatments [166] [199]-[201], and other processes have been used to extract cellulose fibrils from microcrystalline cellulose, wood, tunicate, algae, and bacterial source materials.

Generally, these processes produce high shear, which causes transverse cleavage along the longitudinal axis of the cellulose microfibrillar structure, resulting in the extraction of long cellulose fibrils, also called microfibrillated cellulose. Among these processes, those based on the use of high-pressure homogenizer and microfluidizer equipment are most used in extracting MFC from pulp fibers [202].

The high-pressure homogenization process consists of passing a cellulose slurry into a vessel through very small nozzle at high-pressure. High velocity and pressure produced in the process, as well the impact of the shear forces on fluid generate shear rates in the stream, therefore decreasing the size of fibers into the nanoscale [203]. This process has been used by many researchers as a strategy to break up cellulosic fibers into nanosized component structures, often in combination with other treatments [187] [198] [204]-[210].

Lee et al. [211] produced cellulose nanofibrils using MCC as the starting material through an application of a high-pressure homogenizer at 20,000 psi and treatment consisting of $0,1,2,5,10,15$, and 20 passes. The characterization of the morphology of the material obtained was carried out by scanning electron microscope. The results showed that both the complete fibrillation of the bulk cellulose fibrils to nanoscale and the high aspect ratio was accomplished through the homogenization process.

Zimmermann et al. [192] separated nanofibrillated cellulose in lengths and diameters below $100 \mathrm{~nm}$ from different starting cellulose materials by mechanical dispersion and a high-pressure, of up to 1500 bar, homogenization processes. The treatment resulted in nanoscaled fibril networks.

Davoudpour et al. [209] used a response surface methodology to determine the effects of high-pressure homogenization parameters, specifically pressure and number of cycles, on the isolated yield, crystallinity, and diameter of kenaf bast cellulose nanofibers. The linear terms for the pressure and homogenization cycles had significant effects on the yield of cellulose nanofibers, crystallinity, and diameter, whereas the interaction between the pressure and homogenization cycles had a significant effect on the crystallinity of cellulose nanofibers. The optimized experimental conditions were defined as a homogenization pressure of $56 \mathrm{MPa}, 44 \mathrm{P}$ homogenization cycles, and a $0.1 \mathrm{wt} \%$ fiber suspension concentration. This set of conditions generated cellulose nanofi- 
bers with yield of $89.9 \%$, a degree of crystallinity of $56.5 \%$ and diameter of $8 \mathrm{~nm}$.

Wang et al. [212] produced nanocellulose by dissolving cotton cellulose in an ionic liquid of 1-butyl-3-methylimidazolium chloride, and then subjecting the material to a high-pressure homogenization at $80 \mathrm{MPa}$ for 30 cycles. The resulting nanocellulose presented dimensions of $20 \mathrm{~nm}$ in diameter, as well as a lower thermal stability and crystallinity index. These results showed significant modifications in both the structure and texture treated by high-pressure homogenization. According to this study, a possible explanation was that numbers of hydrogen bonds decreased due to the treatment.

High-pressure homogenization can be considered an efficient method for refining cellulose fibers, because of its high efficiency, simplicity, and lack of organic solvents [213]. However, one of the most important aspects, which can be observed in this process, is that the small size of the orifice of the instrument can cause clogging. Thus, it is necessary to reduce the fiber size before passing samples through the system in order to overcome this limitation.

Similar to the high-pressure homogenization process, microfluidization can also be used to produce micro- fibrillated cellulose. A microfluidizer includes an intensifier pump to increase the pressure, as well as an interaction chamber to defibrillate the fibers through shear and impact forces against the colliding streams and the channel walls [214].

Lee et al. [215] evaluated the effect of time of passing MCC through a microfluidizer at $137.9 \mathrm{MPa}$ on the morphology of cellulose nanofibrils. Results demonstrated that after $10-15$ times of passing the material through the equipment, the aspect ratio of the cellulose fiber bundles increased, whereas additional passes led to the agglomeration of cellulose fibrils, which was attributed to the increase in surface area, and therefore, a higher concentration of hydroxyl groups was found.

Spence et al. [216] conducted a comparative study on the consumption of energy and physical properties of micro-fibrillated cellulose obtained through different processing methods. The MFC was used to produce films. In this research, the cellulose source was processed by homogenization, microfluidization, and micro-grinding, in order to determine the effect of processing on the micro-fibril and film properties, relative to energy consumption. This research has demonstrated that, compared to homogenization, microfluidization with a refining pretreatment and the micro-grinding of wood fibers are production methods that require less energy, and the resulting MFC produced films with improved mechanical properties.

High-intensity ultrasonication is a mechanical process in which oscillating power is used to isolate cellulose fibrils through the hydrodynamic forces of ultrasound [217]. During the process, cavitation leads to a powerful mechanical oscillating power and therefore, high intensive waves, which consists of formation, expansion, and implosion of microscopic gas bubbles when molecules absorb ultrasonic energy [218]. High-intensity ultrasonic treatments generally have been reported to yield shorter, less fibrillar particles of nanocellulose in some cases [187] [219], though thin whiskers were obtained by others following sonication [220].

Structural and functional changes in ultrasound irradiated cellulose have been reported by Liu et al. [221]. These authors reported that the controlled depolymerization of cellulose from plant source can be achieved by employing suitable ultrasonication settings.

Chen et al. [218] individualized cellulose nanofibers from poplar wood in two distinct stages. Initially wood fibers were subjected to a chemical process to eliminate lignin and hemicellulose. Then these fibers were mechanically separated into nanofibers using high-intensity ultrasonication. The diameter distribution of the resulting nanofiber was dependent on the power output of the ultrasound. Microscopy analyses showed that the diameter of the nanofibers was between 5 and $20 \mathrm{~nm}$ when the ultrasonic output power was greater than $1000 \mathrm{~W}$.

Wang and Cheng [200] evaluated the effects of temperature, concentration, size, time, power and distance from probe tip on the degree of fibrillation of some cellulose fibers using high-intensity ultrasonication. They reported that higher fibrillation was caused by higher power and temperature, while longer fibers had lower fibrillation. On the other hand, neither the concentration nor an increased distance between the probe and beaker proved advantageous for fibrillation.

$\mathrm{Li}$ and Liu [222] prepared nanocrystalline cellulose via ultrasound and investigated its reinforcement capability for poly (vinyl alcohol) (PVA) composites. The results showed that was possible to obtain nanocrystalline cellulose using the purely physical method of high-intensity ultrasonication. The obtained nanocrystalline cellulose had diameters between 10 and $20 \mathrm{~nm}$ and lengths between 50 and $250 \mathrm{~nm}$. The progressive increase ultrasonication duration promoted a decrease of length and crystallinity of nanocrystalline cellulose.

Khawas and Deka [166] combined chemical treatment and high-intensity ultrasonication to promote the 
isolation of cellulose nanofibers from culinary banana peel. The results showed that the combination of chemical and physical processes produced cellulose nanofibers with higher crystallinity and enhanced thermal properties and stability.

Cryocrushing is another mechanical method used in the fibrillation process of cellulose. This is a process in which water-swollen cellulosic material is immersed in liquid nitrogen, and then crushed with a mortar and pestle. The brittle fracture of the nanofibers in this mechanical process is made possible by the intense freezing, inducing brittleness, in combination with intense mechanical forces. Cryocrushing has been found to be effective in the case of Kraft fibers after refining, which promotes both delamination and swelling [196] [198].

Alemdar and Sain [198] have extracted cellulose nanofibers from wheat straw by a chemical treatment, resulting in purified cellulose where the material obtained was subjected to cryocrushing to isolate individual nanofibers. The resulting nanofibrils measured $20-120 \mathrm{~nm}$ in width, with the majority measuring $30-40 \mathrm{~nm}$. Wang and Sain used cryocrushing on soybean stock. Transmission electron microscopy showed that the diameter of the nanofibers was in the range of $50-100 \mathrm{~nm}$ and the XRD analysis showed that their degree of crystallinity was about $48 \%$.

All of the mechanical methods listed involve high consumption of energy, which can cause a dramatic decrease in both the yield and fibril length [223]. Thus, current research has focused on environmental conservative, high efficiency and low costs methods to isolate nanocellulose [224]. The pretreatment of cellulose or a combination of two or more methods have produced positive results in this regard.

\section{Polymeric Nanocomposites Based on Cellulose Nanofillers}

The polymer nanocomposites with cellulose nanofiller as reinforcement phase have properties that depend on the characteristics of the cellulosic nanofillers, polymeric matrix and the interaction between them. Polymer matrices of natural [1] [15] [17] [24] [145] [147] [150] [155] [225] and synthetic origin [2] [3] [12]-[14] [18] [156] [174] have been used in the preparation of nanocomposites with cellulose nanofillers. The processing techniques are also an important factor in determining the final properties of cellulose nanocomposites.

\subsection{The Effect of Cellulose Nanofillers Addition on the Properties of Polymeric Nanocomposites}

Several studies have reported the effect of adding cellulose as nanofiller in polymeric matrices on their mechanical [14] [17] [18] [147] [167] [175] [178] [219] [226]-[234], thermal [167] [175] [178] [182] [232] [235]-[238], and barrier [147] [239]-[242] properties, among others.

Regarding the mechanical properties of the cellulose based nanocomposites, many researchers have reported that the addition of cellulose nanofillers on polymer matrices lead to an increased tensile modulus of these materials [18] [227] [230] [235] [243]-[245].

Helbert, Cavaillé and Dufresne [235] reported that latex films of poly (styrene-co-butyl acrylate) containing $30 \mathrm{wt} \%$ of cellulose whiskers exhibited a modulus approximately 1000 times higher than that of the pure polymer. According to these researchers, this pronounced increase in the effect on the modulus is assigned to the geometry and stiffness of the cellulose whiskers.

A study conducted by Cao, Dong, and Li [246] showed that on polyurethane (PU) nanocomposite films obtained by casting, the addition of CNC caused a significant increase in the values of both the Young's modulus and tensile strength of these materials. The Young's modulus increased exponentially relative to the amount of nanocrystals added until the content of $\mathrm{CNC}$ reach $10 \mathrm{wt} \%$. The tensile strength increased from 4.3 to $14.9 \mathrm{MPa}$ when the NCC concentration increased from $0 \mathrm{wt} \%$ to $30 \mathrm{wt} \%$. The researchers concluded that these results on the mechanical properties of the nanocomposites resulted from strong interactions between the matrix and the $\mathrm{CNC}$, which restricted the movement of the chains of the polymer matrix, therefore hindering its deformation.

Nakagaito et al. [13], in their study of nanocomposites based on MFC and poly (lactic acid) (PLA), found a linear increase in the Young's modulus and tensile strength, with an increased MFC concentration. The researchers proposed a new manufacturing process, similar to papermaking, which enables the production of thin sheets made of uniformly dispersed MF with PLA. As a result, the gain in Young's modulus and tensile strength was twice and three times higher, respectively, for the material with $70 \mathrm{wt} \%$ of MFC than that with $10 \mathrm{wt} \%$ of the filler.

Gong et al. [247] conducted a study on the mechanical properties of systems obtained through extrusion of 
poly (vinyl acetate) reinforced with cellulose nanofibrils isolated from the wood of coniferous tree. The results showed that the addition of $10 \mathrm{wt} \%$ of cellulose nanofibers caused an increase of $20 \%$ in tensile strength and $59 \%$ in the Young's modulus of the nanocomposite relative to the values of these properties found in the polymer matrix processed without the addition the nanofiller.

The results of these studies demonstrate that, in general, regardless of the type of polymer employed or processing, the addition of cellulose nanofillers as a reinforcement phase in polymer matrices is able to improve the mechanical performance of the resulting materials. Furthermore, the addition of cellulose nanofiller also affects the elongation of the materials. Samir et al. [248] investigated the mechanical properties of nanocomposites based on polyether and cellulose nanocrystals from tunicate. The stress at breaking and modulus of the materials increased with the $\mathrm{CNC}$ concentration, while the elongation at break decreased from $82 \%$ to $57 \%$, with the incorporation of $1 \mathrm{wt} \% \mathrm{CNC}$ in the polymeric matrix. For larger values of $\mathrm{CNC}$ concentration, the elongation at breaking remained virtually unchanged.

$\mathrm{Wu}$ et al. [230] noted that, while the elongation at breaking increased by the addition of cellulose nanofibrils on the PU matrix, when conventional microscale cellulose was added to the matrix they observed a decrease in this property. According to researchers, this behavior is possibly related to the different cellulose-matrix interactions in nanocomposites than conventional composites. According to Jordan et al. [249], poor interactions between the reinforcement and the matrix cause a decrease in elongation and strength of the material. On the other hand, the modulus does not seem to be dependent on these interactions.

In addition, the concentration of these nanoparticles also has an important effect on some other properties of the nanocomposites. For example, Zimmermann, Pöhler, and Geiger [250], in their work on nanocomposites of PVA and cellulose microfibrils isolated from sulfite pulp, observed that the addition of $5 \mathrm{wt} \%$ of cellulose did not increase the tensile strength or stiffness of the PVA composites. Therefore, minimum filler content is required to induce strong interactions between the polymer and fibrils. Shi et al. [251] produced PLA films containing $1 \mathrm{wt} \%, 5 \mathrm{wt} \%$, and $10 \mathrm{wt} \%$ of CNC. The modulus reached its maximum value in the film containing 5 $\mathrm{wt} \%$ of CNC. Khan et al. [242], while studying chitosan films, found increases of $43 \%$ and $87 \%$ for the modulus of the films with $\mathrm{CNC}$ content of $1 \mathrm{wt} \%$ and $5 \mathrm{wt} \%$, respectively.

However, this optimal concentration of cellulose nanofiller in the nanocomposite may vary depending on the system under study. Wu et al. [230] found that the optimal concentration required to reach the higher values for mechanical properties of elastomeric nanocomposite was $5 \mathrm{wt} \%$ of cellulose. The resulting nanocomposites show an increased strain-to-failure, in addition to an increased stiffness and strength, compared to the unfilled PU. The average true strength for the composition with $5 \mathrm{wt} \%$ of cellulose was $257 \mathrm{MPa}$, compared with 39 MPa for the neat PU, and showed the highest strain-to-failure. The increase of mechanical strength of the composite with cellulose nanofiller addition is evident. However, this increase occurs until a determined amount of nanofiller addition, which, according to Silva et al. [41], in most systems, is around $10 \mathrm{wt} \%$ cellulose. According to this researchers, a cellulose concentration higher than $10 \mathrm{wt} \%$ results in the agglomeration of nanoparticles, which causes a phase separation in the material, and compromises its mechanical properties.

Paralikar, Simonsen and Lombardi [239] analyzed the dispersion of cellulose nanocrystals in PVA and poly (acrylic acid) (PAA) membranes using polarized optical microscopy. The results indicated that the dispersion of nanocrystals in the polymer matrix was homogeneous for composites with a CNC concentration up to $10 \mathrm{wt} \%$. In this study, mechanical tests showed that membranes with $10 \mathrm{wt} \%$ of $\mathrm{CNC}$ had the highest tensile strength, tensile modulus, and toughness of all the membranes studied

Apart from mechanical properties, several studies have shown that the addition of cellulosenanofillers improves the performance of the materials with respect to thermal properties. Studies have shown that the thermal stability of polymer nanocomposites increases with the addition of cellulose nanofillers [235] [237] [252]. Qua et al. [174] reported that the thermal stability of nanocomposites, based on PVA with both MCC and flax nanofibers, increased compared to that of a pure matrix. According to researchers, the initial weight loss at $75^{\circ} \mathrm{C}$ was due to a loss of moisture, which occurred in all samples. The weight loss rate was similar in all materials until the temperature reached $217^{\circ} \mathrm{C}$. Above this temperature, the material decomposition rate showed a significant decrease in the presence of cellulose nanofibers, and reached a maximum difference of about $70^{\circ} \mathrm{C}$, relative to the decomposition temperature of PVA without reinforcement. The researchers attributed this result to the restricted mobility of the polymer chains due to the addition of cellulose nanofibers and their homogeneous distribution in the polymer matrix.

Visakh et al. [253] evaluated the thermal stability of nanocomposites prepared using cellulose nanocrystals 
extracted from bamboo waste, as the reinforcement phase, and natural rubber, as the matrix phase. It was observed that the thermal stability of these materials increased with an increase in the CNC concentration. The increase in the thermal stability for natural rubber by the addition of CNC may be associated with the high amount of interphase with restricted chain mobility generated, due to the large surface area of the nanofiller. As a result of this mobility restriction, the polymer chain scission can be retarded as well escape of byproducts.

In addition to thermal stability, many researchers have investigated the effect of adding cellulose nanofiller on the thermal transitions of the polymer matrix. Some researchers reported an increase in the glass transition temperature, $T_{g}$, of polymeric films with the addition of cellulose nanofillers [15] [254]. In other studies, the effect of the addition of cellulose nanofillers on $T_{g}$ was inconsistent [240] [255] or even insignificant [248]. The results for the melting temperature, $T_{m}$, in polymeric systems with cellulose nanofillers addition have also been controversial in some cases. According to $\mathrm{Wu}$ et al. [230], the presence of cellulose nanofibrils results in a smaller portion of the matrix participating in the glass transition rather than a consistent increase in $\mathrm{T}_{\mathrm{g}}$.

Mathew and Dufresne [255], in their study on nanocomposites prepared from waxy maize starch plasticized with sorbitol and tunicin whiskers, observed that the $\mathrm{T}_{\mathrm{g}}$ of the matrix first increases until the whisker concentration was around $10-15 \mathrm{wt} \%$, and then decreased when higher concentration of cellulose was added. The increase in the $T_{\mathrm{g}}$ was attributed to the increase in crystallinity of the matrix with the addition of up to $15 \mathrm{wt} \%$ of whiskers tunicate. According to researchers, the addition of whiskers leads to a restricted mobility of the amorphous chains of amylopectin in the starch. This restriction on the chain mobility is associated with the formation of physical cross-links induced by crystallization. For contents greater than $15 \mathrm{wt} \%$ of whiskers, researchers suggested that sorbitol was ejected from the crystalline domains into the amorphous domains of the matrix during the crystallization, which led to an increase on mobility of the chains in the amorphous phase and hence decreased the $\mathrm{T}_{\mathrm{g}}$.

Samir et al. [248] developed nanocomposite materials in a film prepared from poly (oxyethylene) and a stable aqueous suspension of cellulose nanocrystals extracted from tunicate. Differential scanning calorimetry (DSC) measurements performed on the nanocomposites showed no significant influence of the CNC content on $\mathrm{T}_{\mathrm{g}}$. The melting temperature is also found to be roughly constant in low concentrations of whiskers, up to $10 \mathrm{wt} \%$. However, for higher filler loading, the $\mathrm{T}_{\mathrm{m}}$ value decreased significantly. Researchers proposed two different effects that could ascribe this decrease of $T_{m}$ values. The first was a morphological phenomenon and could be related to a decrease in the size of polyolefin elastomer (POE) crystallites, due to the formation of a close cellulose network within the matrix, mainly for high filler concentration. This effect could restrict the growth of POE spherulites. The second effect could originate from the strong interactions between ether oxygen groups of POE and hydroxyl groups of cellulose that occur as a result of the high specific area of the whiskers.

Siqueira et al. [238] produced films based on polycaprolactone (PCL) with different concentrations of nanocrystals extracted from a tropical plant, referred to as Luffa cylindrica. The surface of CNC was chemically modified with n-octadecyl isocyanate. Both the modified and unmodified nanocrystals were used to produce the nanocomposites. The thermal properties evaluated showed that the $T_{g}$ value presented a slight increase when adding CNC but no further significant modification was observed when varying the filler concentration. This result suggested that the Luffa cylindrica nanocrystals restrict the rotational backbone motions of the PCL polymer chains through the establishment of hydrogen bonding forces. The addition of surface-chemical grafted nanocrystals promoted a slightly more significant increase in $\mathrm{T}_{\mathrm{g}}$ of the PCL matrix, in comparison to the addition of unmodified nanocrystals, likely due to a greater restriction of mobility. Similar behavior was found in the melting temperature. Adding either unmodified or modified cellulose nanocrystals, the $T_{m}$ presented a slight increase. However, the CNC content did not exert any effect on this parameter.

In some studies, the $\mathrm{T}_{\mathrm{g}}$ is not generally affected by the increase in the concentration of cellulose nanocrystals. Nevertheless, researchers have observed a slight increase in the $T_{g}$ of the polymer matrix [256] [257]. The addition of cellulose nanocrystals in films of poly(3-hydroxybutyrate-co-3-hydroxyvalerate) (PHBV) in the study of $\mathrm{Yu}$, Qin and Zhou [176], promoted an increase on Tm from approximately $130^{\circ} \mathrm{C}$ to $156^{\circ} \mathrm{C}$ for the film with 5 $\mathrm{wt} \%$ of $\mathrm{CNC}$ and to $168^{\circ} \mathrm{C}$ for the film with $10 \mathrm{wt} \%$ of CNC. According to these researchers, this result was an indication that the crystalline perfection of the nanocomposites of PHBV/CNC was enhanced by the presence of the cellulose nanofiller.

Many researches have demonstrated that the addition of cellulose in polymeric matrices affects the crystallinity of the produced materials [258]-[266].

$\mathrm{Lu}$, Wang and Drzal [258] prepared composites based on microfibrillated cellulose and polyvinyl alcohol. In 
this study, the results showed that the crystallinity of PVA presented a small increase with $1 \mathrm{wt} \%$ of MFC, and then it slightly decreases for higher contents of the nanofiller (above $5 \mathrm{wt} \%$ ). According to these authors, the increase in crystallinity is possibly due to the nucleating effect of the nanosized fibers.

Santos and Tavares [267] evaluated the effect of addition of MCC on the crystallinity of the PLA films obtained by casting solutions. The pure PLA film was amorphous, while films with MCC showed crystallinity. The results found by these researchers indicated that the MCC acted as nucleating agent in the system. The addition of cellulose not only promoted the appearance of crystallinity in the films, but also caused a gradual increase in the degree of crystallinity with increasing cellulose concentration.

The same phenomena were observed for tunicin whisker reinforced plasticized starch [255], cellulose nanowhiskers reinforced PHBV [259], cellulose nanocrystals reinforced PCL [266], and for many other materials [18] [259]-[265].

The barrier properties of nanocomposites based on PLA and MCC were studied by Petersson and Oksman [268]. This study showed that the oxygen permeability of PLA greatly increased with the addition of cellulose. Permeability is a function of the distance (tortuous path) that molecules have to travel through the material. One factor that can increase this distance is the shape of reinforcements. In this work, the authors concluded that the geometry of the MCC was not effective in blocking gas molecules, because their nanoparticles shape was not capable to increase the tortuous path and travel through polymeric matrix.

On the other hand, Angellier et al. [269] found interesting barrier properties caused by the addition of starch nanocrystals in the form of platelets in natural rubber. They concluded that, although the starch presents a hydrophilic nature, which could cause an increase in the permeability of water vapor in rubber, the morphology of starch nanocrystals served as a barrier to the transmission of water vapor throughout the elastomeric matrix. The oxygen permeability of the materials was also evaluated. The results showed that the higher the starch content, the lower the permeability to oxygen. The reduction in oxygen permeability was $17.9 \%, 20.3 \%$, and $47 \%$ for compositions containing 10,20 , and $30 \mathrm{wt} \%$ of starch nanocrystals, respectively.

The presence of crystalline fibers has been related to a slower diffusion of water, and hence, a lower permeability [240]. The barrier properties are enhanced if the nanofiller is less permeable and have both a good dispersion in the matrix and a high aspect ratio [270].

Dufresne, Dupeyron, and Vignon [271] observed that the water absorption for the starch films decreases linearly with the increase in the content of cellulose whiskers. Lu, Weng, and Cao [272] found near linear results for the decrease in water absorption with increasing concentration of cellulose whiskers in polymer nanocomposites. Researchers attribute this behavior to the occurrence of hydrogen bonding between the nanocomposite components that tend to stabilize the starch matrix when subjected to atmospheres with high humidity. The high degree of crystallinity of cellulose was also associated to the reduction of water absorption in the nanocomposites.

The water vapor barrier property of nanocrystalline cellulose reinforced chitosan-based biodegradable films was evaluated by Khan et al. [242]. Incorporation of CNC significantly improved the barrier properties. Water vapor permeability of the chitosan/CNC films was decreased by $27 \%$ for the optimum $5 \%(\mathrm{w} / \mathrm{w}) \mathrm{CNC}$ concentration. Swelling studies revealed a decrease in water uptake of the CNC-reinforced chitosan films. Researchers attributed the improved barrier properties to the presence of crystalline regions in the films.

Plackett et al. [273] prepared two types of micro-fibrillated cellulose using either a sulfite pulp containing a high amount of hemicellulose or a carboxymethylated dissolving pulp. Both kinds of MFC were used to produce films with amylopectin. These films were evaluated in relation to the oxygen barrier. The results showed that, regardless of the MFC employed, the film showed low oxygen permeability compared to the permeability presented by the film containing only amylopectin.

Cellulose nanofillers, due to their hydrophilic characteristics, may also be used to obtain barrier membranes to hydrophobic substances such as many toxic chemicals [274]. Paralikar, Simonsen and Lombardi [239] developed polymeric membranes using PVA as the matrix, PAA as crosslinking agent and cellulose nanocrystals. Researchers studied the permeability of these membranes to trichlorethylene, a toxic compound used as solvent and especially for degreasing metal parts. The results showed that the addition of $\mathrm{CNC}$ reduced the permeability of the membranes to trichlorethylene.

\subsection{Compatibility between Cellulose Nanofillers and Polymer Matrices}

The chemical compatibility between the filler and the matrix plays an important role in the dispersion of the par- 
ticles in the matrix and in the adhesion between the phases [42]. Due to the hydrophilic surface of cellulose, interactions between cellulosic nanofillers and hydrophilic matrices are generally satisfactory [275]. On the other hand, the addition of cellulose into hydrophobic matrices results in poor matrix-filler interactions [42].

The addition of cellulose nanofillers in nonpolar matrices, due to its highly polar surface, may lead to some problems associated with low interfacial compatibility, low resistance, water barrier and formation of aggregates [229]. In order to improve the compatibility between cellulose nanofillers and hydrophobic matrices, several cellulose surface modifications have been proposed. These modifications can be performed by different reactions involving the hydroxyl groups, such as esterification, to improve their compatibility with nonpolar polymers [276]. Some of the most common surface chemical modifications of cellulose nanoparticles are summarized in Figure 4.

Freire et al. [229] modified the surface of cellulose fibers by acylation using fatty acid in order to obtain nanocomposites with polyethylene. The chemical modification of the surface of the cellulose fibers resulted in an improved interfacial adhesion between the fibers and the matrix, which was evidenced by an increase in both the mechanical properties and thermal stability and by decreasing the water absorption capacity.

Raquez et al. [277] produced nanocomposites based on PLA and cellulose nanocrystals by extrusion. In this research, the CNC surface was directly modified in an aqueous suspension in the presence of functional trialkoxysilanes, bearing various organic moieties (alkyl, amino, and (meth)acryloxy). Researchers observed that the integrity of the nanocrystals was preserved after silanization, therefore attesting to the efficiency of the process under the investigated conditions. The results showed that there was an increase in both the crystallinity and thermomechanical properties of extruded materials, therefore indicating that the functionalization fulfilled its purpose of reducing the thermal sensitivity of $\mathrm{CNC}$ and strengthen the matrix-filler interactions.

The addition of surfactants may also improve the compatibility between hydrophobic matrices and cellulose [42] [278]-[280]. Hubble et al. [42] proposed that the use of a surfactant would increase the matrix-cellulose compatibility in nanocomposites. The improved performance could be explained not only by the improved wettability and adhesion between phases, but also due to a more uniform distribution of nanofiller within the matrix. However, according to Samir, Alloin, and Dufresne [11], the use of cellulose nanocrystals with chemically modified surfaces has a greater applicability than the use of surfactants as dispersing agents, due to the high specific surface area of the nanocrystals, which requires a high amount of surfactant, leading to an impairment of the mechanical properties of the formed composite.

Grafting the polymer onto the filler is also an effective way to improve the interfacial adhesion of the fillermatrix. A remarkable advantage of this technique is that it permits the addition of dried cellulose nanofiller directly to the melt polymer, which represents an almost essential requirement towards the development of solvent-free industrially-scalable fabrication process [179].

Feng et al. [2] produced bionanocomposites of chitin whisker-graft-polycaprolactone (CHW-g-PCL) by initiating the ring-opening polymerization of caprolactone monomer onto the whiskers surface under microwave radiation. The results showed that an increase of the PCL content in CHW-g-PCL promoted an increase in the strength and elongation of the nanocomposites and also their hydrophobicity. Additionally, the entangling of grafted PCL chains facilitated the transferring of the stress to rigid CHW, and therefore, fully played the reinforcing function of rigid $\mathrm{CHW}$.

Goffin et al. [281] employed a graphitization technique to produce cellulose-based nanocomposites. In this study, poly( $\varepsilon$-caprolactone)-grafted cellulose nanowhiskers were dispersed in the commercial PCL matrix. The results showed that the nanocomposites exhibited an excellent interfacial compatibility of the nanofiller-matrix, and that their thermo-mechanical and rheological performances were largely enhanced. These grafting techniques have shown promising because of the possibility of polymerization of different monomers as well as the possible formation of copolymers.

Chemically modified cellulose nanocrystals (CNCs) synthesized by grafting PHBV onto CNCs were prepared by $\mathrm{Yu}$ and Qin [282]. In this work, a new approach was used to prepare grafted cellulose, combining the advantages of CNCs backbone and hydrophobic PHBV side chains, which can improve the hydrophobicity of CNCs and thus promote the desirable compatibility with hydrophobic polymer matrices. According to the authors, grafted CNCs exhibited great potential for their applications as reinforcing agents for hydrophobic polymer due to their good crystallization ability, better thermal stability, and favorable hydrophobicity.

Another method that has potential to promote improvement in filler-matrix interactions is admicellar polymerization of monomers on the cellulose surface. Admicellar polymerization is one in situ polymerization techniques 


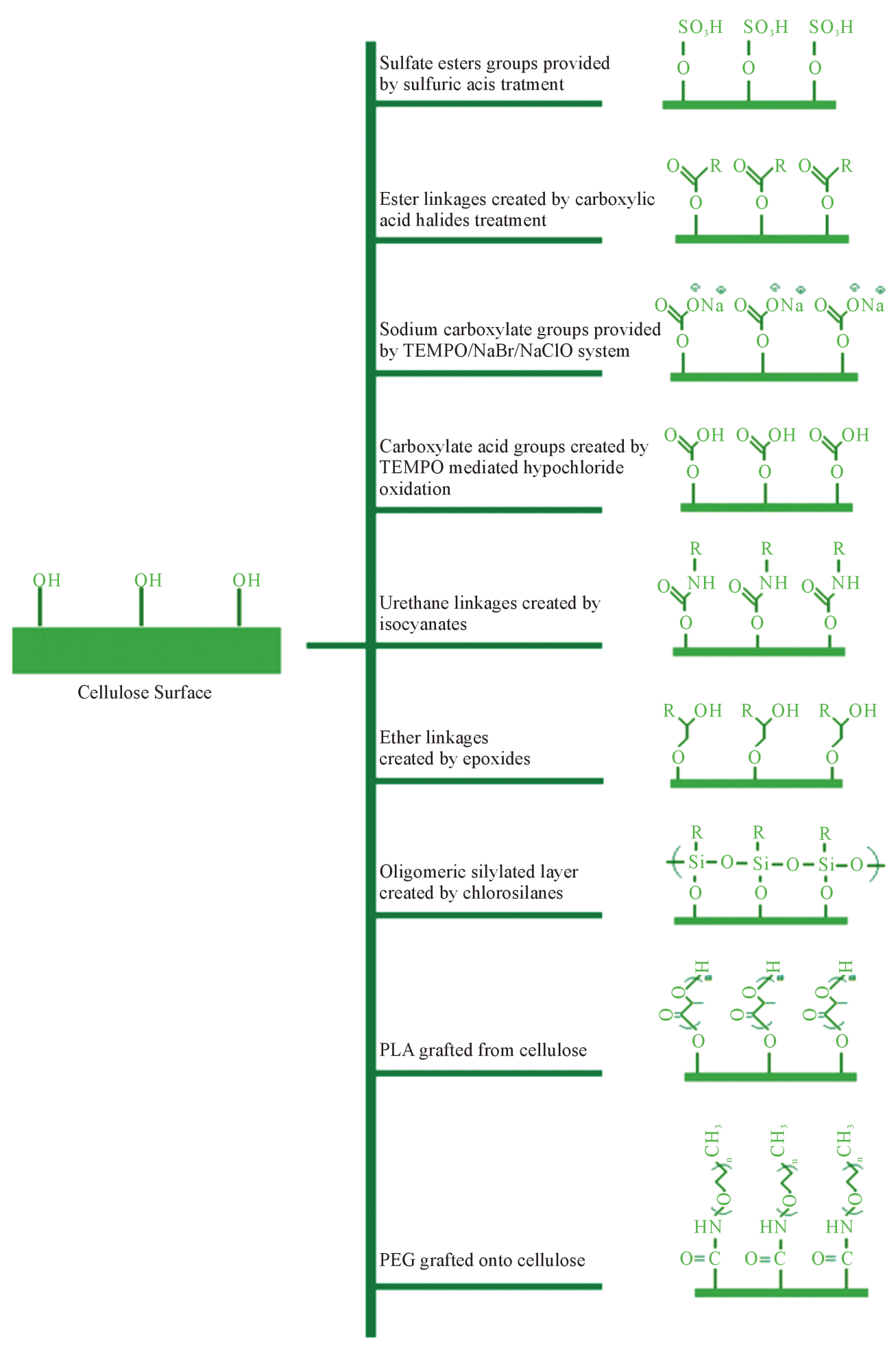

Figure 4. Common surface modifications of cellulose nanoparticles.

used to modify the material surface by coating it with a polymeric nanofilm on the surface [283]-[285]. Admicellar polymerization is a process of four main steps (Figure 5) surfactant adsorption onto the surface of solid particles, resulting in admicelles formation; adsolubilization of monomers into admicelles; polymerization and washing of the outside layer of surfactant [284]. 


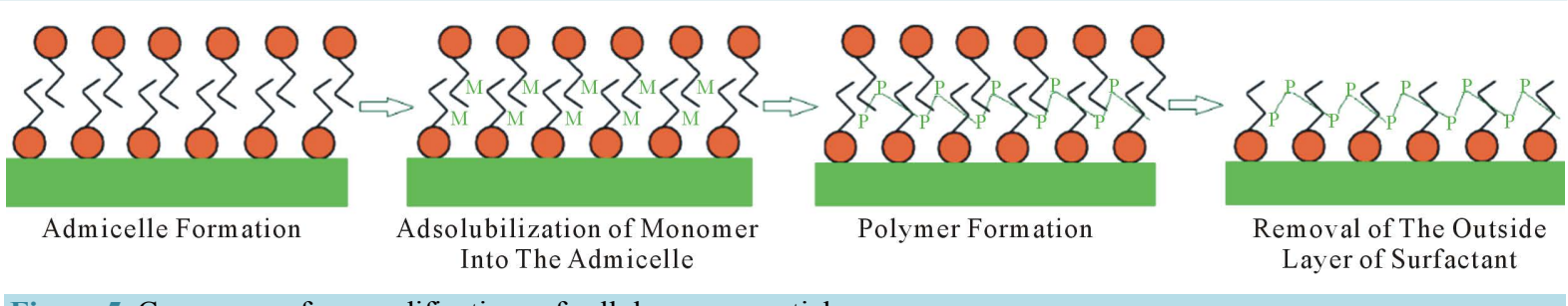

Figure 5. Common surface modifications of cellulose nanoparticles.

Treatment of natural cellulose fiber by admicellar polymerization has been successfully carried out in many researches [283]-[289]. Boufi and Gandini [289] conducted a study on the formation of polymeric films on the surface of cellulose fibers by admicellar polymerization. They used styrene, methyl methacrylate and 2-ethyl hexylacrylate as monomers in the reaction. The results showed that admicellar polymerization produced a strong increase in the hydrophobic characteristics of the cellulosic surface.

Tragoonwichian, O'rear and Yanumet [285] studied the use of admicellar polymerization to improve UV protection and water repellency of cotton fabric. A characterization of the surface of the fabric confirmed the presence of a thin polymer film and produced a significant reduction in the UV transmission in the analyzed sample. The UV protection factor in the cotton fabric increased from 4 to a value greater than 40 .

Sangthong, Pongprayoon and Yanumet [286] studied the admicellar polymerization of sisal fiber and the effectiveness of its use as reinforcing filler in order to improve the mechanical performance of an unsaturated polyester resin. The results showed that addition of nanofiller treated by this method in the polymer matrix provided a better performance with regard to tensile properties, flexural, impact resistance and hardness of the materials produced.

This method provides some important advantages over conventional methods for surface coating. The process is simple and the use of chemicals is minimal [290] [291].

Another advantage is that the process is environmentally friendly, since it can be performed in an aqueous solution, without any organic solvents.

\subsection{Cellulose Processing of Polymer Nanocomposites Reinforced with Cellulose Nanofillers}

The processing techniques used to obtain the nanocomposites are of great importance in determining the final properties of these materials. The choice of processing technique is conditioned to the intrinsic properties of the cellulose nanofiller and the matrix, such as solubility, dispersibility and degradation [11].

Some processing techniques have been used to make cellulose nanofiller reinforced polymer nanocomposites such as solution casting [15] [17] [18] [42] [90] [161] [259] melt-compounding [139] [161] [179] [259] [281] [292] partial dissolution [139] and electrospinning [293]-[298].

In solution casting process, the cellulose nanofillers can be dispersed in water or in an organic medium, depending on the nature of the polymer matrix.

Because of the high stability of aqueous dispersions of cellulose nanofiller, the water has been the preferred medium to preparing these nanocomposites [138]. Due to this fact, water soluble matrices have been widely used in the production of nanocellulose-based nanocomposites [11].

Many researchers have produced composite materials with cellulosic materials in hydrophilic matrix polymers. A commonly applied method is to cast a film, and then to allow it to dry by slow evaporation [18] [101] [103] [299]-[301].

Regarding the nonpolar polymer nanocomposites, an alternative way to process these materials consists in the dispersion of the matrix in an adequate organic medium. In this case, the cellulose nanoparticles should be coated with a surfactant or have their surface chemically modified in order to reduce their surface energy and improving their dispersibility/compatibility with nonpolar media.

In general, the process to obtain nanocellulose-based nanocomposites by casting starts with mixing the nanoparticles suspension and the dispersed or solubilized polymer matrix. Homogeneous suspensions of this mixture are generally obtained by magnetic stirring. A step of degassing under vacuum to remove air of the suspensions can be proceeded [185]. The nanocomposite films can be produced from this mixture by three general techniques that consist in casting on a suitable surface followed by evaporation, freeze-drying and compression 
molding, or freeze-drying, extruding, and then compression molding the mixture [27]. There is also a less common technique for obtaining these nanocomposites films by casting that consists in their production by crosslinking in situ an unsaturated matrix after solvent casting using a thermal or photo cross-linking agent [302].

Cellulose-based nanocomposites films can also be prepared by partial dissolution. Generally, this process is used in the preparing of "all-cellulose" nanocomposites or composites. In these materials, both the filler and the matrix are cellulose. Therefore, the matrix and reinforcement phases are completely compatible with each other, allowing efficient stress transfer and adhesion at their interface [303] [304]. Different cellulosic micro- and nanofibers have been used to produce all-cellulose composites and nanocomposites, including ramie fibers [305] [306], microcrystalline cellulose [307], filter paper [308] [309], bacterial cellulose, [310] commercial microfibrillated cellulose [309], cellulose nanowhiskers [311] and beech pulp [312]. This approach consists of a partial cellulose dissolution step and subsequent regeneration of dissolved cellulose in the presence of undissolved fibres. Different solvents have been used to produce these materials, including $N, N$-dimethylacetamide/lithium chloride ( $\mathrm{DMAc} / \mathrm{LiCl}$ ) [305] [307] [308] [310], ionic liquid [309] and sodium hydroxide ( $\mathrm{NaOH}$ )/urea [311]. Among these solvents, $\mathrm{DMAc} / \mathrm{LiCl}$ is especially popular because of its ability to dissolve cellulose under moderate conditions [304]. "All-cellulose" composites have also been produced via solution casting of a mixture of cellulose suspensions [307].

Cellulose-based nanocomposites can also be produced by melt-compounding methods. Melt-compounding processes involve the incorporation of cellulose nanofillers into thermoplastic polymers by using thermal-mechanical mixing (compounding) and the extrusion of the melt mixture. After these processes, the composite material also can be compression molded into specific test specimen geometries [139] [161].

The use of cellulosic material has been reported in some studies involving compounding and extrusion [281] [292] [313]-[318]. There are two main challenges when including cellulosic materials in extruded or compounding composites products. One of them is the possibility of degradation of the cellulose, and the other is about the dispersion of the cellulose particles in the matrix. Generally, cellulose nanoparticles are obtained as a stable suspension of the material in aqueous medium and then they are isolated by drying and the obtained powder is used in melt-compounding. The hydrophilicity of cellulose promotes irreversible agglomeration during drying and aggregation in nonpolar matrices during the compounding or extrusion because of the formation of additional hydrogen bonds between amorphous parts of the cellulose nanoparticles [319].

The degradation of cellulose during these processes can result from either the high temperatures required in compounding and extruding or the very high shear stresses employed. Thus, a careful control of processing parameters is needed to minimize the cellulose degradation.

Hajji et al. [320] studied the tensile behavior of poly (Sco-BuA)/tunicin whisker composites prepared from three different manners that were extrusion, hot pressing and evaporation. The authors classified processing methods in ascending order of their reinforcement efficiency (tensile modulus and strength). According to the authors, the ascending order of efficiency was extrusion, hot pressing, and evaporation. This evolution was associated to probable breakage and/or orientation of whiskers during processing.

Chazeau et al. [313] attempted to minimize mechanical breakdown of cellulose nanoparticles by heating the mixture just enough to melt the polymeric matrix, then mixing to get a good dispersion of the nanoparticles, and finally molding the composite structure. The analysis of the materials by transmission electron microscopy showed that the typical length of the whiskers was not modified during the processing of the composites.

Bondeson and Oksman [317] used an anionic surfactant (5, 10 and $20 \mathrm{wt} \%)$ to improve the dispersion of cellulose whiskers in the PLA matrix to produce nanocomposites by extrusion process. The results showed that increased surfactant content resulted in improved dispersion but at the same time degraded the PLA matrix. The results from mechanical testing showed a maximum modulus for the composite with $5 \mathrm{wt} \%$ of surfactant and as the surfactant content increased, the tensile strength and elongation at break was improved compared to its unreinforced counterpart.

Soulestin et al. [318] pioneered an innovative way to improve the uniform distribution of a cellulosic component in a polymeric matrix. The authors injected water into the mixture during extrusion of cellulose fibers in low-density polyethylene (LDPE). However, there was evidence of substantial degradation of the cellulose when using this approach.

Oksman et al. [252] pump the cellulose nanocrystals during the melt extrusion of cellulose nanowhiskersreinforced biodegradable matrices nanocomposite, and the results indicate that the dispersion of cellulose nanofibers improved when they were incorporated into the two-screw extruder with liquid feeding compared to dry 
mixing.

Recently, Pereda, Kissi and Dufresne [321] used a physical compatibilization approach using poly (ethylene oxide) (PEO) as compatibilizing agent to improve the dispersibility of CNCs into linear low density polyethylene (LLDPE) processed by melt extrusion.

Studies on reactive extrusion of polymers in presence of fillers or nanofillers have been reported as strategy to enhance the compatibilization between hydrophobic matrices and hydrophilic cellulose [281] [322]-[325]. Goffin et al. [281] prepared nanocomposites based on PCL reinforced with surface-grafted cellulose nanowhiskers via reactive extrusion processing. The results showed that an excellent dispersion of the cellulose nanowhiskers within PCL matrix was achieved and the thermo-mechanical and rheological performances were largely enhanced as a consequence of the excellent interfacial compatibility. Recent studies [324] on in situ reactive extrusion of polyhydroxybutyrate (PHB) with cellulose in the presence of dicumyl peroxide initiator led to improvement in the glass transition temperature and onset degradation temperature $\left(\sim 22^{\circ} \mathrm{C}\right)$.

Electrospinning has been also used to produce cellulose-based nanocomposites. Electrospinning is a variation on fiber spinning processes [27]. Spinning is a process that involves forcing a polymer melt or solution through a small orifice, and then coagulating the polymer in a solution or drying atmosphere [27]. Electrostatic fiber spinning or "electrospinning" utilizes an electrical charge to draw a positively charged polymer solution from an orifice to a collector [303]. This technique is capable of producing micrometer to nanometer-scale fibers, and it is a versatile method of preparing fibers with diameters ranging from several microns down to $100 \mathrm{~nm}$ [326].

In general, the cellulose nanoparticles are dispersed within a given medium, and polymer solutions are mixed with the cellulose nanoparticle dispersion. This solution/suspension is typically maintained at a set temperature within an insulated syringe with a metal needle. With application of pressure and high voltage, a jet of solution/ suspension is accelerated out of the needle and toward a target (e.g. vertical plate, continuous spooler) at a given distance under a given set of environmental conditions [326]. The solvent evaporates as the fiber moves between the source and the collector, causing the polymer to coagulate and form a composite fiber [27].

Cellulose whiskers obtained from bacteria were incorporated into POE nanofibers with a diameter of less than $1 \mu \mathrm{m}$ by the electrospinning process to improve the mechanical properties of the electrospun fibers [327]. The cellulose whiskers were found to be globally well embedded and aligned inside the fibers, even though they were partially aggregated. Electrospun polystyrene (PS) [293], PVA [296] and PCL [328] microfibers reinforced with cellulose nanocrystals were obtained by electrospinning.

\section{Applications}

Cellulose nanoparticles present the potential for diverse industrial applications, and their use in nanocomposites has been extensively studied [42]. Within the field of nanocomposites, several possible applications have been cited including solidified liquid crystals for optical applications such as security paper [329], and mechanical reinforcing whiskers for low-thickness polymer electrolytes in lithium batteries [103] [330] [331]. Recently, an organic display system has been developed from nanocellulose. It is expected that this type of product could bring about a transformative change in communication display systems, and the technology seems likely to spread throughout different sectors of the electronics and telecommunications industries [42].

Hubbe and Rojas cite other possible applications of cellulose whisker technology, including their use in medicine [42]. By modifying the cellulose surface with a fluorophore, Dong and Roman [332] produced fluorescently labeled cellulose nanocrystals that could be used as markers in nanomedicine. The results showed that fluorescent cellulose nanocrystals allow the use of fluorescence techniques, such as spectrofluorometry, fluorescent microscopy, and flow cytometry. This technology enables the study of various mechanisms, such as the interaction between cellulose nanocrystals and cells, and the in vivo biodistribution of cellulose nanocrystals.

The biomedical community has begun to exploit the hydrophilic qualities of cellulose in the development of hydrogels. Hydrogels have proved to be highly suitable materials for medical and pharmaceutical applications such as drug delivery, tissue scaffolds, actuators, sensors, and valves [42].

Several investigators have suggested the use of cellulose nanoparticles in the development of support scaffolds for tissue or bone regeneration [333]-[335]. The function of these scaffolds is to provide not only a surface for cell growth, but also the mechanical and structural support needed for the original tissue while the new tissue is formed [336].

Pooyan, Tannenbaum, and Garmestani [337] used cellulose acetate propionate and cellulose nanocrystals to 
develop nanocomposite scaffolds for vascular tissue engineering. The resulting vascular biomaterial exhibited excellent mechanical properties when tested at human body temperature. The researchers primarily attributed these results to the unique properties of the cellulose nanocrystal dispersion and the mechanical stability of the rigid interconnected percolation network within the polymer matrix.

Sasha et al. [338] developed and evaluated the biological properties of cellulose-hydroxyapatite nanocomposite membranes for bone regeneration. Membranes were tested in tibial bone defects of rats after 1, 4, and 16 weeks. No inflammatory reaction was observed in vivo after one week, and the defects were completely filled with new bone tissue at four weeks, thereby demonstrating the efficacy of the membranes for bone regeneration.

Cherian et al. [339] developed cellulose nanocomposites with nanofibres isolated from pineapple leaf fibers and polyurethane (PU) to produce implants for medical application. The medical implants were fabricated in desired molds using non-woven nanocellulose mats and PU film with $5 \mathrm{wt} \%$ of nanocellulose. The produced material proved to be very versatile, having the potential to be used in wide range of medical applications, such as cardiovascular implants, scaffolds for tissue engineering, repair of articular cartilage, vascular grafts, urethral catheters, mammary prostheses, penile prostheses, adhesion barriers and artificial skin.

In addition to these applications, cellulose-based nanocomposites have the potential for use in various types of barrier film applications. Dogan and McHugh [229] described the preparation of edible films that can serve as protective coatings on food.

\section{Conclusions}

Interest in the use of cellulose nanoparticles as components within polymeric nanocomposites has been growing in the last several years due to their wide availability, low weight, biodegradability, renewability, and outstanding mechanical properties.

Cellulose has been shown to be a material with great potential to improve the performance of polymeric matrices, especially with regard to mechanical resistance. Due to these improved properties, there is a wide range of potential applications for nanocellulose-based nanocomposites, such as packaging products, electronics, cosmetics and biomedical applications.

However, to take advantage of the great potential of these materials, some aspects should not be disregarded. The major challenges to the use of cellulose nanofillers in nanocomposite production have involved the dispersion of the nanoparticles, and the lack of cellulosic surface compatibility with a variety of polymers. In addition, the water-swellable nature of cellulose can be a concern in various composite materials.

Recent studies show that considerable progress has been achieved in addressing these challenges, thereby improving the potential to use cellulose-based nanofillers in nanocomposites designed for use in a wide range of applications.

\section{Acknowledgements}

The authors would like to thank the Brazilian funding agencies CAPES and FAPERJ for the financial support.

\section{References}

[1] Petersson, L., Mathew, A.P. and Oksman, K. (2009) Dispersion and Properties of Cellulose Nanowhiskers and Layered Silicates in Cellulose Acetate Butyrate Nanocomposites. Journal of Applied Polymer Science, 112, 2001-2009. http://dx.doi.org/10.1002/app.29661

[2] Feng, L., Zhou, Z., Dufresne, A., Huang, J., Wei, M. and An, L. (2009) Structure and Properties of New Thermoforming Bionanocomposites Based on Chitin Whisker-Graft-Polycaprolactone. Journal of Applied Polymer Science, 112, 2830-2837. http://dx.doi.org/10.1002/app.29731

[3] Goetz, L., Mathew, A., Oksman, K., Gatenholm, P. and Ragauskas, A.J. (2009) A Novel Nanocomposite Film Prepared from Crosslinked Cellulosic Whiskers. Carbohydrate Polymers, 75, 85-89. http://dx.doi.org/10.1016/j.carbpol.2008.06.017

[4] Mecking, S. (2004) Nature or Petrochemistry? - Biologically Degradable Materials. Angewandte Chemie, International Edition, 43, 1078-1085. http://dx.doi.org/10.1002/anie.200301655

[5] Farsani, R.E., Nasab, Z.H., Khalili, S.M.R. and Soleimani, N. (2012) Mechanical Characterization of Nanoclay Reinforced Polypropylene Composites at High Temperature Subjected to Tensile Loads. Advanced Materials Research, 488-489, 567-571. http://dx.doi.org/10.4028/www.scientific.net/AMR.488-489.567 
[6] Medeiros, V.N., Araújo, E.M., Maia, L.F., Pereira, O.D., Arimateia, R.R. and Paz, R.A. (2008) Desenvolvimento de Nanocompósitos de Poliamida6/Polietileno/Argila Organofílica: O Efeito do Compatibilizante PE-g-MA no Comportamento Reológico da Mistura. Polímeros, 18, 302-306. http://dx.doi.org/10.1590/S0104-14282008000400008

[7] Azeredo, H.M.C. (2009) Nanocomposites for Food Packaging Applications. Food Research International, 42, 12401253. http://dx.doi.org/10.1016/j.foodres.2009.03.019

[8] Bledzki, A.K. and Gassan, J. (1999) Composites Reinforced with Cellulose Based Fibres. Progress in Polymer Science, 24, 221-274. http://dx.doi.org/10.1016/S0079-6700(98)00018-5

[9] Nakagaito, A.N., Iwamoto, S. and Yano, H. (2005) Bacterial Cellulose: The Ultimate Nano-Scalar Cellulose Morphology for the Production of High Strength Composites. Applied Physics A: Materials Science \& Processing, 80, $93-$ 97. http://dx.doi.org/10.1007/s00339-004-2932-3

[10] Taylor, N.G. (2008) Cellulose Biosynthesis and Deposition in Higher Plants. New Phytologist, 178, $239-252$. http://dx.doi.org/10.1111/j.1469-8137.2008.02385.x

[11] Samir, M.A.S.A., Alloin, F. and Dufresne, A. (2005) Review of Recent Research into Cellulosic Whiskers, Their Properties and Their Application in Nanocomposite Field. Biomacromolecules, 6, 612-626. http://dx.doi.org/10.1021/bm0493685

[12] Iwatake, A., Nogi, M. and Yano, H. (2008) Cellulose Nanofiber-Reinforced Polylactic Acid. Composites Science and Technology, 68, 2103-2106. http://dx.doi.org/10.1016/j.compscitech.2008.03.006

[13] Nakagaito, A.N., Fujimura, A., Sakai, T., Hama, Y. and Yano, H. (2009) Production of Microfibrillated Cellulose (MFC)-Reinforced Polylactic Acid (PLA) Nanocomposites from Sheets Obtained by a Papermaking-Like Process. Composites Science and Technology, 69, 1293-1297. http://dx.doi.org/10.1016/i.compscitech.2009.03.004

[14] Lin, N., Chen, G., Huang, J., Dufresne, A. and Chang, P.R. (2009) Structure and Mechanical Properties of Poly (Lactic Acid): A Case of Cellulose Whisker-Graft-Polycaprolactone. Journal of Applied Polymer Science, 113, 3417-3425. http://dx.doi.org/10.1002/app.30308

[15] Anglès, M.N. and Dufresne, A. (2000) Plasticized Starch/Tunicin Whiskers Nanocomposites. 1. Structural Analysis. Macromolecules, 33, 8344-8353. http://dx.doi.org/10.1021/ma0008701

[16] Huang, Q., Huang, J. and Chang, P.R. (2014) Polycaprolactone Grafting of Cellulose Nanocrystals in Ionic Liquid [BMIM]Cl. Wuhan University Journal of Natural Sciences, 19, 117-122. http://dx.doi.org/10.1007/s11859-014-0987-3

[17] Babaee, M., Jonoobi, M., Hamzeh, Y. and Ashori, A. (2015) Biodegradability and Mechanical Properties of Reinforced Starch Nanocomposites Using Cellulose Nanofibers. Carbohydrate Polymers, 132, 1-8. http://dx.doi.org/10.1016/j.carbpol.2015.06.043

[18] Santos, F.A. and Tavares, M.I.B. (2015) Development of Biopolymer/Cellulose/Silica Nanostructured Hybrid Materials and Their Characterization by NMR Relaxometry. Polymer Testing, 47, 92-100. http://dx.doi.org/10.1016/j.polymertesting.2015.08.008

[19] Rosa, M.F., Medeiros, E.S., Malmonje, J.A., Wood, D.F., Mattoso, L.H.C., Orts, W.J. and Imam, S.H. (2008) Extração e Caracterização de Whiskers de Celulose de Fibra de Coco. Resumos do Congresso Brasileiro de Engenharia e Ciência dos Materiais, Porto de Galinhas, 4050-4058.

[20] Mccarthy, S.P. (2003) Biodegradable Polymers. In: Andrady, A.L., Ed., Plastics and the Environment, John Wiley and Sons, Inc., New York, 359-377. http://dx.doi.org/10.1002/0471721557.ch9

[21] Yan, Z., Chen, S., Wang, H., Wang, B., Wang, C. and Jiang, J. (2008) Cellulose Synthesized by Acetobacter xylinum in the Presence of Multi-Walled Carbon Nanotubes. Carbohydrate Research, 343, 73-80. http://dx.doi.org/10.1016/j.carres.2007.10.024

[22] Pérez, S. and Mazeau, K. (2005) Conformations, Structures, and Morphologies of Celluloses. In: Dimitriu, S., Ed., Polysaccharides: Structural Diversity and Functional Versatility, Marcel Dekker, Inc., New York, 41-68.

[23] Chanzy, H. (1990) Aspects of Cellulose Structure. In: Kennedy, J.F., Phillips, G.O. and Williams P.A., Eds., Cellulose Sources and Exploitation: Industrial Utilization, Biotechnology and Physico-Chemical Properties, Ellis Horwood, Inc., New York, 3-12.

[24] Rosas, K.A. (2008) Biocompósitos de Almidón Termoplástico con Microfibras de Celulosa. Tesís Maestrado, Instituto de investigación en ciencia aplicada y tecnología avanzada del instituto politecnico nacional, Altamira.

[25] Zhang, Y.H.P., Cui, J.B., Lynd, L.R. and Kuang, L.R. (2006) A Transition from Cellulose Swelling to Cellulose Dissolution by O-Phosphoric Acid: Evidence from Enzymatic Hydrolysis and Supramolecular Structure. Biomacromolecules, 7, 644-648. http://dx.doi.org/10.1021/bm050799c

[26] John, M.J. and Thomas, S. (2008) Biofibres and Biocomposites. Carbohydrate Polymers, 71, 343-364. http://dx.doi.org/10.1016/j.carbpol.2007.05.040

[27] Moon, R.J., Martini, A., Nairn, J., Simonsen, J. and Youngblood, J. (2011) Cellulose Nanomaterials Review: Structure, 
Properties and Nanocomposites. Chemical Society Reviews, 40, 3941-3994. http://dx.doi.org/10.1039/c0cs00108b

[28] Labafzadeh, S.R. (2015) Cellulose-Based Materials. Academic Dissertation, Faculty of Science of the University of Helsinki, Helsinki.

[29] Silva, D.J. and D’Almeida, M.L.O. (2009) Nanocristais de Celulose. Revista O Papel, 70, 34-52. http://www.revistaopapel.org.br/noticia-anexos/1311883542 1b4f1881c01129ce934b0cb4b4ebb9ab 343315426.pdf

[30] Van de Vyver, S., Geboers, J., Jacobs, P.A. and Sels, B.F. (2011) Recent Advances in the Catalytic Conversion of Cellulose. Chem Cat Chem, 3, 82-94. http://dx.doi.org/10.1002/cctc.201000302

[31] Nishiyama, Y., Sugiyama, J., Chanzy, H. and Langan, P. (2003) Crystal Structure and Hydrogen Bonding System in Cellulose 1(Alpha), from Synchrotron X-Ray and Neutron Fiber Diffraction. Journal of the American Chemical Society, 125, 14300-14306. http://dx.doi.org/10.1021/ja037055w

[32] Dugan, J.M., Gough, J.E. and Eichhorn, S.J. (2013) Bacterial Cellulose Scaffolds and Cellulose Nanowhiskers for Tissue Engineering. Nanomedicine, 8, 297-298.

[33] Wuestenberg, T. (2014) Cellulose and Cellulose Derivatives in the Food Industry: Fundamentals and Applications. Wiley-VCH, Weinheim.

[34] Klock, U., Muniz, G.I.B. and Hernandez, J.A. (2005) Química da Madeira. Curitiba: Fundação de Pesquisas Florestais do Paraná-Fupef, Curitiba.

[35] Kulshreshtha, A.K. and Dweltz, N.E. (1973) Para Crystalline Lattice Disorder in Cellulose-1. Reappraisal of the Application of the Two-Phase Hypothesis to the Analysis of Powder X-Ray Diffractograms of Native and Hydrolyzed Cellulosic Materials. Journal of Polymer Science Polymer Physics Edition, 11, 487-497.

[36] Yamamoto, H. and Horii, F. (1993) CPMAS Carbon-13 NMR Analysis of the Crystal Transformation Induced for Valonia Cellulose by Annealing at High Temperatures. Macromolecules, 26, 1313-1317. http://dx.doi.org/10.1021/ma00058a020

[37] Sen, S., Martin, J.D. and Argyropoulos, D.S. (2013) Review of Cellulose Non-Derivatizing Solvent Interactions with Emphasis on Activity in Inorganic Molten Salt Hydrates. ACS Sustainable Chemistry \& Engineering, 1, 858-870. http://dx.doi.org/10.1021/sc400085a

[38] Adel, A.M., El-Wahab, Z.H.A., Ibrahim, A.A. and Al-Shemy, M.T. (2011) Characterization of Microcrystalline Cellulose Prepared from Lignocellulosic Materials. Part II: Physicochemical Properties. Carbohydrate Polymers, 83, 676687. http://dx.doi.org/10.1016/j.carbpol.2010.08.039

[39] Silva, T.A. (2005) Caracterização Química de Polpas Kraft Recicladas Obtidas por Tratamento com Oxigênio e Sistema Lacase-HBT. Dissertação de Mestrado, Universidade Federal do Paraná, Curitiba.

[40] Silva, R., Haraguchi, S.K., Muniz, E.C. and Rubira, A.F. (2009) Aplicações de Fibras Lignocelulósicas na Química de Polímeros e em Compósitos. Química Nova, 32, 661-671. http://dx.doi.org/10.1590/S0100-40422009000300010

[41] Monrroy, M., García, J.-R., Mendonça, R.T., Baeza, J. and Freer, J. (2012) Kraft Pulping of Eucalyptus globulus as a Pretreatment for Bioethanol Production by Simultaneous Saccharification and Fermentation. Journal of the Chilean Chemical Society, 57, 1113-1117. http://dx.doi.org/10.4067/S0717-97072012000200012

[42] Hubbe, M.A., Rojas, O.J, Lucia, L.A. and Sain, M. (2008) Cellulosic Nanocomposites: A Review. Bioresources, 3, 929-980.

[43] Baptista, C., Robert, D. and Duarte, A.P. (2008) Relationship between Lignin Structure and Delignification Degree in Pinus pinaster Kraft Pulps. Bioresource Technology, 99, 2349-2356. http://dx.doi.org/10.1016/j.biortech.2007.05.012

[44] Urruzola, I., Robles, E., Serrano, L. and Labidi, J. (2015) Cellulose-Based Graft Copolymer for Toxic Ion and Organic Persistent Pollutants Removal. In: Thakur, V.K., Ed., Cellulose-Based Graft Copolymers: Structure and Chemistry, CRC Press, Boca Raton, 271-281. http://dx.doi.org/10.1201/b18390-14

[45] Gibbons, J.H. (1989) Technologies for Reducing Dioxin in the Manufacture of Bleached Wood Pulp: Background Paper Paperback, Washington DC.

[46] Brasileiro, L.B., Colodette, J.L. and Piló-Veloso, D. (2001) A Utilização de Perácidos na Deslignificação e no Branqueamento de Polpas Celulósicas. Química Nova, 24, 819-829. http://dx.doi.org/10.1590/S0100-40422001000600020

[47] Vázquez, G., González-Álvarez, J., Rodríguez, E.M., Freire, S. and Antorrena, G. (2002) Preliminary Studies on TCF Bleaching of Pinus pinaster Acetosolv Pulps. Bioresource Technology, 81, 141-149. http://dx.doi.org/10.1016/S0960-8524(01)00115-8

[48] Huang, G.-L., Shi, J.X. and Langrish, T.A.G.G. (2008) Environmentally Friendly Bagasse Pulping with $\mathrm{NH}_{4} \mathrm{OH}-$ KOH-AQ. Journal of Cleaner Production, 16, 1287-1293. http://dx.doi.org/10.1016/j.jclepro.2007.06.011

[49] Sten, H., Bengt, O.L. and Ulla, S. (1953) The Rate Dominating Reaction of the Delignification of Wood Powder with Sulfite Solutions. Svensk Papperstidning, 56, 645-690. 
[50] Sixta, H. (1998) Comparative Evaluation of Different Concepts of Sulfite Pulping Technology. Das Papier, 52, 239249.

[51] Jerônimo, L.H., Foelkel, C.E.B. and Frizzo, S.M.B. (2000) Adição de Antraquinona na Polpação Alcalina de Eucalyptus saligna. Ciência Florestal, 10, 31-37.

[52] El-Ghany, N.A.A. (2009) Organosolv Pulping of Cotton Linters. Cellulose Chemistry and Technology, 43, 419-426.

[53] Castellan, A., Perez, D.S., Nourmamode, A., Grelier, S., Terrones, M.G.H., Machado, A.E.H. and Ruggiero, R. (1999) The Improvement of the Bleaching of Peroxyformic Sugar Cane Bagasse Pulp by Photocatalysis and Photosensitization. Journal of Brazilian Chemical Society, 10, 197-202. http://dx.doi.org/10.1590/S0103-50531999000300007

[54] Sun, J.X., Sun, X.F., Zhao, H. and Sun, R.C. (2004) Isolation and Characterization of Cellulose from Sugarcane Bagasse. Polymer Degradation and Stability, 84, 331-339. http://dx.doi.org/10.1016/j.polymdegradstab.2004.02.008

[55] Son, H.J., Heo, M.S., Kim, Y.G. and Lee, S.J. (2001) Optimization of Fermentation Conditions for the Production of Bacterial Cellulose by a Newly Isolated Acetobacter. Biotechnology and Applied Biochemistry, 33, 1-5. http://dx.doi.org/10.1042/BA20000065

[56] Gatenholm, P. and Klemm, D. (2010) Bacterial Nanocellulose as a Renewable Material for Biomedical Applications. MRS Bulletin, 35, 208-213. http://dx.doi.org/10.1557/mrs2010.653

[57] Jonas, R. and Farah, L.F. (1998) Production and Application of Microbial Cellulose. Polymer Degradation and Stability, 59, 101-106. http://dx.doi.org/10.1016/S0141-3910(97)00197-3

[58] Esa, F., Tasirin, S.M. and Rahman, N.A. (2014) Overview of Bacterial Cellulose Production and Application. Agriculture and Agricultural Science Procedia, 2, 113-119. http://dx.doi.org/10.1016/j.aaspro.2014.11.017

[59] Castro, C., Zuluaga, R., Putaux, J.L., Caro, G., Mondragon, I. and Gañán, P. (2011) Structural Characterization of Bacterial Cellulose Produced by Gluconacetobacter swingsii Sp. from Colombian Agroindustrial Wastes. Carbohydrate Polymers, 84, 96-102. http://dx.doi.org/10.1016/j.carbpol.2010.10.072

[60] Klemm, D., Schumann, D., Udhardt, U. and Marsch, S. (2001) Bacterial Synthesized Cellulose: Artificial Blood Vessels for Microsurgery. Progress in Polymer Science, 26, 1561-1603. http://dx.doi.org/10.1016/S0079-6700(01)00021-1

[61] Nogi, M. and Yano, H. (2008) Transparent Nanocomposites Based on Cellulose Produced by Bacteria Offer Potential Innovation in the Electronics Device Industry. Advanced Materials, 20, 1849-1852. http://dx.doi.org/10.1002/adma.200702559

[62] Yamanaka, S. and Watanabe, K. (1994) Applications of Bacterial Cellulose. In: Gilbert, D.R., Ed., Cellulosic Polymers: Blends and Composites, Hanser, New York, 207-215.

[63] Iguchi, M., Yamanaka, S. and Budhiono, A. (2000) Bacterial Cellulose: A Masterpiece of Nature's Arts. Journal of Materials Science, 35, 261-270. http://dx.doi.org/10.1023/A:1004775229149

[64] Kanjanamosit, N., Muangnapohand, C. and Phisalaphong, M. (2010) Biosynthesis and Characterization of Bacteria Cellulose-Alginate Film. Journal of Applied Polymer Science, 115, 1581-1588. http://dx.doi.org/10.1002/app.31138

[65] Santos, S.M., Carbajo, J.M. and Villar, J.C. (2013) The Effect of Carbon and Nitrogen Sources on Bacterial Cellulose Production and Properties from Gluconacetobacter sucrofermentans CECT 7291 Focused on Its Use in Degraded Paper Restoration. Bioresources, 8, 3630-3645. http://dx.doi.org/10.15376/biores.8.3.3630-3645

[66] Watanabe, K., Tabuchi, M., Morinaga, Y. and Yoshinaga, F. (1998) Structural Features and Properties of Bacterial Cellulose Produced in Agitated Culture. Cellulose, 5, 187-200. http://dx.doi.org/10.1023/A:1009272904582

[67] Tanskul, S., Amornthatree, K. and Jaturonlak, N. (2013) A New Cellulose-Producing Bacterium, Rhodococcus Sp. MI 2: Screening and Optimization of Culture Conditions. Carbohydrate Polymers, 92, 421-428. http://dx.doi.org/10.1016/j.carbpol.2012.09.017

[68] Shi, Q.S., Feng, J., Li, W.R., Zhou, G., Chen, A.M., Ouyang, Y.S. and Chen, Y.B. (2013) Effect of Different Conditions on the Average Degree of Polymerization of Bacterial Cellulose Produced by Gluconacetobacter intermedius BC-41. Cellulose Chemical Technology, 47, 503-508.

[69] Ishihara, M., Matsunaga, M., Hayashi, N. and Tisler, V. (2002) Utilization of Dxylose as Carbon Source for Production of Bacterial Cellulose. Enzyme and Microbial Technology, 31, 986-991. http://dx.doi.org/10.1016/S0141-0229(02)00215-6

[70] Son, H.J., Kim, H.G., Kim, K.K., Kim, H.S., Kim, Y.G. and Lee, S.J. (2003) Increased Production of Bacterial Cellulose by Acetobacter Sp. V6 in Synthetic Media under Shaking Culture Conditions. Bioresource Technology, 86, 215219. http://dx.doi.org/10.1016/S0960-8524(02)00176-1

[71] Keshk, S. and Sameshima, K. (2005) Evaluation of Different Carbon Sources for Bacterial Cellulose Production. African Journal of Biotechnology, 4, 478-482.

[72] Mikkelsen, D., Flanagan, B.M., Dykes, G.A. and Gidley, M.J. (2009) Influence of Different Carbon Sources on Bac- 
terial Cellulose Production by Gluconacetobacter xylinus Strain ATCC 53524. Journal of Applied Microbiology, 107, 576-583. http://dx.doi.org/10.1111/j.1365-2672.2009.04226.x

[73] Jung, H.I., Jeong, J.H., Lee, O.M., Park, G.T., Kim, K.K., Park, H.C., Lee, S.M., Kim, Y.G. and Son, H.J. (2010) Influence of Glycerol on Production and Structural-Physical Properties of Cellulose from Acetobacter Sp. V6 Cultured in Shake Flasks. Bioresource Technology, 101, 3602-3608. http://dx.doi.org/10.1016/j.biortech.2009.12.111

[74] Masaoka, S., Ohe, T. and Sakota, N. (1993) Production of Cellulose from Glucose by Acetobacter xylinum. , 75, 18-22. http://dx.doi.org/10.1016/0922-338X(93)90171-4

[75] Oikawa. T., Morino. T. and Ameyama, M. (1995) Production of Cellulose from D-Arbitol by Acetobacter xylinum KU-1. Bioscience, Biotechnology Biochemistry, 59, 1564-1565. http://dx.doi.org/10.1271/bbb.59.1564

[76] Keshk, S. and Sameshima, K. (2006) Influence of Lignosulfonate on Crystal Structure and Productivity of Bacterial Cellulose in a Static culture. Enzyme and Microbial Technology, 40, 4-8. http://dx.doi.org/10.1016/j.enzmictec.2006.07.037

[77] Gomes, F.P., Silva, N.H.C.S., Trovatti, E., Serafim, L.S., Duarte, M.F., Silvestre, A.J.D., Neto, C.P. and Freire, C.S.R. (2013) Production of Bacterial Cellulose by Gluconacetobacter sacchari Using Dry Olive Mill Residue. Biomass and Bioenergy, 55, 205-211. http://dx.doi.org/10.1016/j.biombioe.2013.02.004

[78] Yamamoto, H. and Horii, F. (1994) In Situ Crystallization of Bacterial Cellulose I. Influences of Polymeric Additives, Stirring and Temperature on the Formation Celluloses $\mathrm{I}_{\alpha}$ and $\mathrm{I}_{\beta}$ as Revealed by Cross Polarization/Magic Angle Spinning (CP/MAS) ${ }^{13}$ C NMR Spectroscopy. Cellulose, 1, 57-66. http://dx.doi.org/10.1007/BF00818798

[79] Tokoh, C., Takabe, K., Fujita, M. and Saiki, H. (1998) Cellulose Synthesized by Acetobacter xylinum in Presence of Acetylglucomannan. Cellulose, 5, 249-261. http://dx.doi.org/10.1023/A:1009211927183

[80] Keshk, J. (2014) Bacterial Cellulose Production and Its Industrial Applications. Bioprocessing \& Biotechniques, 4, 150. http://dx.doi.org/10.4172/2155-9821.1000150

[81] Colvin, J.R. (1980) The Biosynthesis of Cellulose: Plant Biochemistry. Academic Press Inc., New York. http://dx.doi.org/10.1016/b978-0-12-675403-2.50020-x

[82] Nakashima, K., Sugiyama, J. and Satoh, N. (2008) A Spectroscopic Assessment of Cellulose and the Molecular Mechanisms of Cellulose Biosynthesis in the Ascidian Ciona intestinalis. Marine Genomics, 1, 9-14. http://dx.doi.org/10.1016/j.margen.2008.01.001

[83] Hirose, E., Kimura, S., Itoh, T. and Nishikawa, J. (1999) Tunic Morphology and Cellulosic Components of Pyrosomas, Doliolids, and Salps (Thaliacea, Urochordata). The Biological Buletin, 196, 113-120. http://dx.doi.org/10.2307/1543173

[84] Berrill, N.J. (1950) The Tunicata. Ray Society Publications, 133, 1-354.

[85] Hassanzadeh, M. (2011) Composition and Application Potentials of Scandinavian Tunicates. Master Thesis, KTH Royal Institute of Technology, Stockholm.

[86] Satoshi, K. and Itoh, T. (2007) Biogenesis and Function of Cellulose in the Tunicates. In: Brown Jr., R.M. and Saxena, I.M., Eds., Cellulose, Molecular and Structural Biology, Springer, New Work, 217-236.

[87] Kimura, S. and Itoh, T. (2004) Cellulose Synthesizing Terminal Complexes in the Ascidians. Cellulose, 11, $377-383$. http://dx.doi.org/10.1023/B:CELL.0000046414.72903.33

[88] Daele, Y.V., Revol, J.F., Gaill, F. and Goffinet, G. (1992) Characterization and Supramolecular Architecture of the Cellulose-Protein Fibrils in the Tunic of the Sea Peach (Halocynthia papillosa, Ascidiacea, Urochordata). Biology of the Cell, 76, 87-96. http://dx.doi.org/10.1016/0248-4900(92)90198-A

[89] De Leo, G., Patricolo, E. and Lunetta, G.D.A. (1977) Studies on the Fibrous Components of the Test of Ciona intestinalis Linnoeus. I. Cellulose-Like Polysaccharide. Acta Zoologica, 58, 135-141. http://dx.doi.org/10.1111/j.1463-6395.1977.tb00248.x

[90] Zhang, D., Zhang, Q., Gao, X. and Piao, G. (2013) A Nanocellulose Polypyrrole Composite Based on Tunicate Cellulose. International Journal of Polymer Science, 2013, 1-6. http://dx.doi.org/10.1155/2013/175609

[91] Yuan, H., Nishiyama, Y., Wada, M. and Kuga, S. (2006) Surface Acylation of Cellulose Whiskers by Drying Aqueous Emulsion. Biomacromolecules, 7, 696-700. http://dx.doi.org/10.1021/bm050828j

[92] Khandelwal, M. and Windle, A.H. (2013) Self-Assembly of Bacterial and Tunicate Cellulose Nanowhiskers. Polymer, 54, 5199-5206. http://dx.doi.org/10.1016/j.polymer.2013.07.033

[93] Hirose, E. (2009) Ascidian Tunic Cells: Morphology and Functional Diversity of Free Cells outside the Epidermis. Invertebrate Biology, 128, 83-96. http://dx.doi.org/10.1111/j.1744-7410.2008.00153.x

[94] Sugiyama, J., Persson, J. and Chanzy, H. (1991) Combined Infrared and Electron Diffraction Study of the Polymorphism of Native Celluloses. Macromolecules, 24, 2461-2466. http://dx.doi.org/10.1021/ma00009a050

[95] Kuga, S., Kim, D.-Y., Nishiyama, Y. and Brown, R.M. (2002) Nanofibrillar Carbon from Native Cellulose. Molecular 
Crystals and Liquid Crystals, 387, 13-19. http://dx.doi.org/10.1080/713738864

[96] Saito, T., Kuramae, R., Wohlert, J., Berglund, L.A. and Isogai, A. (2013) An Ultrastrong Nanofibrillar Biomaterial: The Strength of Single Cellulose Nanofibrils Revealed via Sonication-Induced Fragmentation. Biomacromolecules, 14, 248-253. http://dx.doi.org/10.1021/bm301674e

[97] Helbert, W., Nishiyama, Y., Okano, T. and Sugiyama, J. (1998) Molecular Imaging of Halocynthia papillosa Cellulose. Journal of Structural Biology, 124, 42-50. http://dx.doi.org/10.1006/jsbi.1998.4045

[98] Kimura, S. and Itoh, T. (1996) New Cellulose Synthesizing Complexes (Terminal Complexes) Involved in Animal Cellulose Biosynthesis in the Tunicate Metandrocarpa uedai. Protoplasma, 194, 151-163. http://dx.doi.org/10.1007/BF01882023

[99] Wardrop, A.B. (1970) The Structure and Formation of the Test of Pyura stolonifera (Tunicata). Protoplasma, 70, 73-86. http://dx.doi.org/10.1007/BF01276843

[100] Favier, V., Chanzy, H. and Cavaille, J.Y. (1995) Polymer Nanocomposites Reinforced by Cellulose Whiskers. Macromolecules, 28, 6365-6367. http://dx.doi.org/10.1021/ma00122a053

[101] Ruiz, M.M., Cavaille, J.Y., Dufresne, A., Graillat, C. and Gerard, J.F. (2001) New Waterborne Epoxy Coatings Based on Cellulose Nanofillers. Macromolecular Symposia, 169, 211-222. http://dx.doi.org/10.1002/1521-3900(200105)169:1<211::AID-MASY211>3.0.CO;2-H

[102] Goussé, C., Chanzy, H., Excoffier, G., Soubeyrand, L. and Fleury, E. (2002) Stable Suspensions of Partially Silylated Cellulose Whiskers Dispersed in Organic Solventes. Polymer, 43, 2645-2651. http://dx.doi.org/10.1016/S0032-3861(02)00051-4

[103] Schroers, M., Kokil, A. and Weder, C. (2004) Solid Polymer Electrolytes Based on Nanocomposites of Ethylene Oxide-Epichlorohydrin Copolymers and Cellulose Whiskers. Journal of Applied Polymer Science, 93, 2883-2888. http://dx.doi.org/10.1002/app.20870

[104] Samir, M.A.S.A., Alloin, F. and Dufresne, A. (2006) High Performance Nanocomposite Polymer Electrolytes. Composite Interfaces, 13, 545-559. http://dx.doi.org/10.1163/1568554067774408656

[105] Dufresne, A. (2006) Comparing the Mechanical Properties of High Performance Polymer Nanocomposites from Biological Sources. Journal of Nanoscience and Nanotechnology, 6, 322-330.

[106] Podsiadlo, P., Sui, L., Elkasabi, Y., Burgardt, P., Lee, J., Miryala, A., Kusumaatmaja, W., Carman, M.R., Shtein, M., Kieffer, J., Lahann, J. and Kotov, N.A. (2007) Layerby-Layer Assembled Films of Cellulose Nanowires with Antireflective Properties. Langmuir, 23, 7901-7906. http://dx.doi.org/10.1021/la700772a

[107] Van den Berg, O., Capadona, J.R. and Weder, C. (2007) Preparation of Homogeneous Dispersions of Tunicate Cellulose Whiskers in Organic Solvents. Biomacromolecules, 8, 1353-1357. http://dx.doi.org/10.1021/bm061104q

[108] Elazzouzi-Hafraoui, S., Nishiyama, Y., Putaux, J.-L., Heux, L., Dubreuil, F. and Rochas, C. (2008) The Shape and Size Distribution of Crystalline Nanoparticles Prepared by Acid Hydrolysis of Native Cellulose. Biomacromolecules, 9, 5765. http://dx.doi.org/10.1021/bm700769p

[109] Tang, L. and Weder, C. (2010) Cellulose Whisker/Epoxy Resin Nanocomposites. ACS Applied Materials \& Interfaces, 2, 1073-1080. http://dx.doi.org/10.1021/am900830h

[110] Pullawan, T., Wilkinsonb, A.N., Zhang, L.N. and Eichhorn, S.J. (2014) Deformation Micromechanics of All-Cellulose Nanocomposites: Comparing Matrix and Reinforcing Components. Carbohydrate Polymers, 100, 31-39. http://dx.doi.org/10.1016/j.carbpol.2012.12.066

[111] Zhao, Y. and Li, J. (2014) Excellent Chemical and Material Cellulose from Tunicates: Diversity in Cellulose Production Yield and Chemical and Morphological Structures from Different Tunicate Species. Cellulose, 21, 3427-3441. http://dx.doi.org/10.1007/s10570-014-0348-6

[112] Kouzuma, A. and Watanabe, K. (2015) Exploring the Potential of Algae/Bactéria Interactions. Current Opinion in Biotechnology, 33, 125-129. http://dx.doi.org/10.1016/j.copbio.2015.02.007

[113] Lee, S.Y., Ahn, J.W., Hwangm, H.J. and Lee, S.B. (2011) Seaweed Biomass Resources in Korea. Korean Society for Biotechnology and Bioengineering Journal, 26, 267-276. http://dx.doi.org/10.7841/ksbbj.2011.26.4.267

[114] Mohammad, S.M., Rahman, N.A., Khalil, M.S. and Abdullah, S.R.S. (2014) An Overview of Biocellulose Production Using Acetobacter xylinum Culture. Advances in Biological Research, 8, 307-313.

[115] Baldan, B., Andolfo, P., Navazio, L., Tolomio, C. and Mariani, P. (2001) Cellulose in Algal Cell Wall: An "in Situ" Localization. European Journal of Histochemistry: EJH, 45, 51-56. http://dx.doi.org/10.4081/1613

[116] Frei, E. and Preston, R.D. (1964) Non-Cellulosic Structural Polysaccharides in Algal Cell Walls. II. Association of Xylan and Mannan in Porphyra umbilicalis. Proceedings of the Royal Society B, 160, 314-327. http://dx.doi.org/10.1098/rspb.1964.0042 
[117] Kloareg, B. and Quatrano, R.S. (1988) Structure of the Cell Walls of Marine Algae and Ecophysiological Functions of the Matrix Polysaccharides. Oceanography and Marine Biology: An Annual Review, 26, 259-315.

[118] Sjostrom, E. (1993) Wood Chemistry_Fundamentals and Applications. Academic Press, San Diego.

[119] Nicolai, E. and Preston, R.D. (1952) Cell-Wall Studies in the Chlorophyceae. I. A General Survey of Submicroscopic Structure in Filamentous Species. Proceedings of the Royal Society B, 140, 245-274. http://dx.doi.org/10.1098/rspb.1952.0061

[120] George, J. and Sabapathi, S.N. (2015) Cellulose Nanocrystals: Synthesis, Functional Properties, and Applications. Journal of Nanotechnology, Science and Applications, 4, 45-54. http://dx.doi.org/10.2147/NSA.S64386

[121]Ek, R., Gustafsson, C., Nutt, A., Iversen, T. and Nyström, C. (1998) Cellulose Powder from Cladophora Sp. Algae. Journal of Molecular Recognition, 11, 263-265. http://dx.doi.org/10.1002/(SICI)1099-1352(199812)11:1/6<263::AID-JMR437>3.0.CO;2-G

[122] Vuong-Roger, Chanzy, H. and Sugiyama, J. (1992) The Cellulose System of Cladophora densa. Biology of the Cell, 75, 264. http://dx.doi.org/10.1016/0248-4900(92)90174-Y

[123] Wiencke, C., Gorham, J., Tomos, D. and Davenport, J. (1992) Incomplete Turgor Adjustment in Cladophora rupestris under Fluctuating Salinity Regimes. Estuarine Coastal and Shelf Science, 34, 413-427. http://dx.doi.org/10.1016/S0272-7714(05)80079-4

[124] Kim, N.H., Herth, W., Vuong, R. and Chanzy, H. (1996) The Cellulose System in the Cell Wall of Micrasterias. Journal of Structural Biology, 117, 195-203. http://dx.doi.org/10.1006/jsbi.1996.0083

[125] Hanley, S.J., Revol, J.F., Godbout, L. and Gray, D.G. (1997) Atomic Force Microscopy and Transmission Electron Microscopy of Cellulose from Micrasterias denticulata; Evidence for a Chiral Helical Microfibril Twist. Cellulose, 4, 209-220. http://dx.doi.org/10.1023/A:1018483722417

[126] Revol, J.K. (1982) On the Cross-Sectional Shape of Cellulose Crystallites in Valonia ventricosa. Carbohydrate Polymers, 2, 123-134. http://dx.doi.org/10.1016/0144-8617(82)90058-3

[127] Sugiyama, J., Harada, H., Fujiyoshi, Y. and Uyeda, N. (1985) Lattice Images from Ultrathin Sections of Cellulose Microfibrils in the Cell Wall of Valonia macrophysa Kütz. Planta, 166, 161-168. http://dx.doi.org/10.1007/BF00397343

[128] Hanley, S.J., Giasson, J., Revol, J.F. and Gray, D.G. (1992) Atomic Force Microscopy of Cellulose Microfibrils: Comparison with Transmission Electron Microscopy. Polymer, 33, 4639-4642. http://dx.doi.org/10.1016/0032-3861(92)90426-W

[129] Imai, T. and Sugiyama, J. (1998) Nanodomains of $\mathrm{I}_{\alpha}$ and $\mathrm{I}_{\beta}$ Cellulose in Algal Microfibrils. Macromolecules, 31, 62756279. http://dx.doi.org/10.1021/ma980664h

[130] Mihranyan, A., Llagostera, A.P., Karmhag, R., Strømme, M. and Ek, R. (2004) Moisture Sorption by Cellulose Powders of Varying Crystallinity. International Journal of Pharmaceutics, 269, 433-442. http://dx.doi.org/10.1016/j.ijpharm.2003.09.030

[131] Mihranyan, A., Edsman, K. and Strømme, M. (2007) Rheological Properties of Cellulose Hydrogels Prepared from Cladophora Cellulose Powder. Food Hydrocolloids, 21, 267-272. http://dx.doi.org/10.1016/j.foodhyd.2006.04.003

[132] Gelin, K., Mihranyan, A., Razaq, A., Nyholm, L. and Strømme, M. (2009) Potential Controlled Anion Absorption in a Novel High Surface Area Composite of Cladophora Cellulose and Polypyrrole. Electrochimica Acta, 54, 3394-3401. http://dx.doi.org/10.1016/j.electacta.2009.01.010

[133] Jmel, M.A., Messaouda, G.B., Marzouki, M.N., Mathlouthi, M. and Smaali, I. (2016) Physico-Chemical Characterization and Enzymatic Functionalization of Enteromorpha Sp. Cellulose. Carbohydrate Polymers, 135, 274-279. http://dx.doi.org/10.1016/j.carbpol.2015.08.048

[134] Ishii, D., Saito, T. and Isogai, A. (2011) Viscoelastic Evaluation of Average Length of Cellulose Nanofibres Prepared by TEMPO-Mediated Oxidation. Biomacromolecules, 12, 548-550. http://dx.doi.org/10.1021/bm1013876

[135] Andresen, M., Johansson L.S., Tanem, B.S. and Stenius, P. (2006) Properties and Characterization of Hydrophobized Microfibrillated Cellulose. Cellulose, 13, 665-677. http://dx.doi.org/10.1007/s10570-006-9072-1

[136] Stenstad, P., Andresen, M., Tanem, B.S. and Stenius, P. (2008) Chemical Surface Modifications of Microfibrillated Cellulose. Cellulose, 15, 35-45. http://dx.doi.org/10.1007/s10570-007-9143-y

[137] Siro, I. and Plackett, D. (2010) Microfibrillated Cellulose and New Composite Materials: A Review. Cellulose, 17, 459-494. http://dx.doi.org/10.1007/s10570-010-9405-y

[138] Siqueira, G., Bras, J. and Dufresne, A. (2010) Cellulosic Bionanocomposites: A Review of Preparation, Properties and Applications. Polymers, 2, 728-765. http://dx.doi.org/10.3390/polym2040728

[139] Eichhorn, S.J, Dufresne, A., Aranguren, M., Marcovich, N.E., Capadona, J.R., Rowan, S.J., Weder, C., Thielemans, 
W., Roman, M., Renneckar, S., Gindl, W., Veigel, S., Keckes, J., Yano, H., Abe, K., Nogi, M., Nakagaito, A.N., Simonsen, J., Bismarck, A., Berglund, L.A. and Peijis, T. (2010) Review: Current International Research into Cellulose Nanofibres and Nanocomposites. Journal of Materials Science, 45, 1-33. http://dx.doi.org/10.1007/s10853-009-3874-0

[140] Klemm, D., Kramer, F., Moritz, S., Lindström, T., Ankerfors, M., Gray, D. and Dorris, A. (2011) Nanocelluloses: A New Family of Nature-Based Materials. Angewandte Chemie International Edition, 50, 5438-5466. http://dx.doi.org/10.1002/anie.201001273

[141] Charreau, H., Foresti, M.L. and Vazquez, A. (2013) Nanocellulose Patents Trends: A Comprehensive Review on Patents on Cellulose Nanocrystals, Microfibrillated and Bacterial Cellulose. Recent Patents on Nanotechnology, 7, 56-80. http://dx.doi.org/10.2174/187221013804484854

[142] Rodriguez, N.L.G., Thielemans, W. and Dufresne, A. (2006) Sisal Cellulose Whiskers Reinforced Polyvinyl Acetate Nanocomposites. Cellulose, 13, 261-270. http://dx.doi.org/10.1007/s10570-005-9039-7

[143] Beck-Candanedo, S., Roman, M. and Gray, D.G. (2005) Effect of Reaction Conditions on the Properties and Behavior of Wood Cellulose Nanocrystal Suspensions. Biomacromolecules, 6, 1048-1054. http://dx.doi.org/10.1021/bm049300p

[144] Bai, W., Holbery, J. and Li, K. (2009) A Technique for Production of Nanocrystalline Cellulose with a Narrow Size Distribution. Cellulose, 16, 455-465. http://dx.doi.org/10.1007/s10570-009-9277-1

[145] Zhao, Y., Zhang, Y., Lindström, M.E. and Li, J. (2015) Tunicate Cellulose Nanocrystals: Preparation, Neat Films and Nanocomposite Films with Glucomannans. Carbohydrate Polymers, 117, 286-296. http://dx.doi.org/10.1016/j.carbpol.2014.09.020

[146] Ljungberg, N., Cavaille, J.Y. and Heux, L. (2006) Nanocomposites of Isotactic Polypropylene Reinforced with Rod-Like Cellulose Whiskers. Polymer, 47, 6285-6292. http://dx.doi.org/10.1016/j.polymer.2006.07.013

[147] Bras, J., Hassan, M.L., Bruzesse, C., Hassan, E.A., Nahla, A., El-Wakil, N.A. and Dufresne, A. (2010) Mechanical, Barrier, and Biodegradability Properties of Bagasse Cellulose Whiskers Reinforced Natural Rubber Nanocomposites. Industrial Crops and Products, 32, 627-633. http://dx.doi.org/10.1016/j.indcrop.2010.07.018

[148] Bras, J., Viet, D., Bruzzese, C. and Dufresne, A. (2011) Correlation between Stiffness of Sheets Prepared from Cellulose Whiskers and Nanoparticles Dimensions. Carbohydrate Polymers, 84, 211-215. http://dx.doi.org/10.1016/j.carbpol.2010.11.022

[149] Hassan, M.L., Moorefield, C.M., Elbatal, H.S., Newkome, G.R., Modarelli, D.A. and Romano, N.C. (2012) Fluorescent Cellulose Nanocrystals via Supramolecular Assembly of Terpyridine-Modified Cellulose Nanocrystals and Terpyridine-Modified Perylene. Materials Science and Engineering: B, 177, 350-358. http://dx.doi.org/10.1016/j.mseb.2011.12.043

[150] Ma, Q., Hu, D. and Wang, L. (2016) Preparation and Physical Properties of Tara Gum Film Reinforced with Cellulose Nanocrystals. International Journal of Biological Macromolecules, 86, 606-612. http://dx.doi.org/10.1016/j.ijbiomac.2016.01.104

[151] Lima, M.M.S. and Borsali, R. (2004) Cellulose Microcrystals: Structure, Properties, and Applications. Macromolecular Rapid Communications, 25, 771-787. http://dx.doi.org/10.1002/marc.200300268

[152] Shim, B.S., Podsiadlo, P., Lilly, D.G., Agarwal, A., Leet, J., Tang, Z., Ho, S., Ingle, P., Paterson, D., Lu, W. and Kotov, N.A. (2007) Nanostructured Thin Films Made by Diewetting Method of Layer-by-Layer Assembly. Nano Letters, 7, 3266-3273. http://dx.doi.org/10.1021/n1071245d

[153] Rosa, M.F., Medeiros, E.S., Malmonge, J.A., Gregorski, K.S., Wood, D.F., Mattoso, L.H.C., Glenn, G., Orts, W.J. and Imam, S.H. (2010) Cellulose Nanowhiskers from Coconut Husk Fibers: Effect of Preparation Conditions on Their Thermal and Morphological Behavior. Carbohydrate Polymers, 81, 83-92. http://dx.doi.org/10.1016/j.carbpol.2010.01.059

[154] Bitinis, N., Verdejo, R., Bras, J., Fortunati, E., Kenny, J.M., Torre, L. and López-Manchado, M.A. (2013) Poly (Lactic Acid)/Natural Rubber/Cellulose Nanocrystal Bionanocomposites Part I. Processing and Morphology. Carbohydrate Polymers, 96, 611-620. http://dx.doi.org/10.1016/j.carbpol.2013.02.068

[155] Alves, J.S., Reis, K.C., Menezes, E.G.T., Pereira, F.V. and Pereira, J. (2015) Effect of Cellulose Nanocrystals and Gelatin in Corn Starch Plasticized Films. Carbohydrate Polymers, 115, 215-222. http://dx.doi.org/10.1016/j.carbpol.2014.08.057

[156] Bajpai, S.K., Pathak, V. and Soni, B. (2015) Minocycline-Loaded Cellulose Nano Whiskers/Poly (Sodium Acrylate) Composite Hydrogel Films as Wound Dressing. International Journal of Biological Macromolecules, 79, 76-85. http://dx.doi.org/10.1016/j.ijbiomac.2015.04.060

[157] El-Saied, H., Basta, A.H. and Gobran, R.H. (2004) Research Progress in Friendly Environmental Technology for the Production of Cellulose Products (Bacterial Cellulose and Its Application). Polymer-Plastics Technology and Engineering, 43, 797-820. http://dx.doi.org/10.1081/PPT-120038065

[158] Brown, E.E. and Laborie, M.P.G. (2007) Bloengineering Bacterial Cellulose/Poly (Ethylene Oxide) Nanocomposites. 
Biomacromolecules, 8, 3074-3081. http://dx.doi.org/10.1021/bm700448x

[159] Wan, W.K., Hutter, J.L., Millon, L.E. and Guhados, G. (2006) Bacterial Cellulose and Its Nanocomposites for Biomedical Applications. In: Oksman, K. and Sain, M., Eds., Cellulose Nanocomposites. Processing Characterization, and Properties, ACS Symposium Series, Washington DC, 221-241. http://dx.doi.org/10.1021/bk-2006-0938.ch015

[160] Barud, H.S., Barrios, C., Regiani, T., Marques, R.F.C., Verelst, M., Dexpert-Ghys, J., Messaddeq, Y. and Ribeiro, S.J.L. (2008) Self-Supported Silver Nanoparticles Containing Bacterial Cellulose Membranes. Materials Science \& Engineering C: Materials for Biological Applications, 28, 515-518. http://dx.doi.org/10.1016/j.msec.2007.05.001

[161] Habibi, Y., Lucia, L.A. and Rojas, O.J. (2010) Cellulose Nanocrystals: Chemistry, Self-Assembly, and Applications. Chemical Reviews, 110, 3479-3500. http://dx.doi.org/10.1021/cr900339w

[162] Mihranyan, A. (2011) Cellulose from Cladophorales Green Algae: From Environmental Problem to High-Tech Composite Materials. Journal of Applied Polymer Science, 119, 2449-2460. http://dx.doi.org/10.1002/app.32959

[163] Stelte, W. and Sanadi, A.R. (2009) Preparation and Characterization of Cellulose Nanofibers from Two Commercial Hardwood and Softwood Pulps. Industrial \& Engineering Chemical Research, 48, 11211-11219. http://dx.doi.org/10.1021/ie9011672

[164] Dufresne, A. (2012) Nanocellulose: From Nature to High Performance Tailored Materials. De Gruyter, Berlin. http://dx.doi.org/10.1515/9783110254600

[165] Velásquez-Cock, J., Gañán, P., Posada, P., Castro, C., Serpa, A., Gómez, C., Putaux, J.-L. and Zuluaga, R. (2016) Influence of Combined Mechanical Treatments on the Morphology and Structure of Cellulose Nanofibrils: Thermal and Mechanical Properties of the Resulting Films. Industrial Crops and Products, 85, 1-10. http://dx.doi.org/10.1016/j.indcrop.2016.02.036

[166] Khawas, P. and Deka, S.C. (2016) Isolation and Characterization of Cellulose Nanofibers from Culinary Banana Peel Using High-Intensity Ultrasonication Combined with Chemical Treatment. Carbohydrate Polymers, 137, 608-616. http://dx.doi.org/10.1016/j.carbpol.2015.11.020

[167] Yu, H.-Y., Qin, Z.-Y., Liu, L., Yang, X.-G., Zhou, Y. and Yao, J.-M. (2013) Comparison of the Reinforcing Effects for Cellulose Nanocrystals Obtained by Sulfuric and Hydrochloric Acid Hydrolysis on the Mechanical and Thermal Properties of Bacterial Polyester. Composites Science and Technology, 87, 22-28. http://dx.doi.org/10.1016/j.compscitech.2013.07.024

[168] Guo, J., Guo, X., Wang, S. and Yin, Y. (2016) Effects of Ultrasonic Treatment during Acid Hydrolysis on the Yield, Particle Size and Structure of Cellulose Nanocrystals. Carbohydrate Polymers, 135, 248-255. http://dx.doi.org/10.1016/j.carbpol.2015.08.068

[169] Dong, S., Bortner, M.J. and Roman, M. (2016) Analysis of the Sulfuric Acid Hydrolysis of Wood Pulp for Cellulose Nanocrystal Production: A Central Composite Design Study. Industrial Crops and Products. (In Press) http://www.sciencedirect.com/science/article/pii/S0926669016300486 http://dx.doi.org/10.1016/j.indcrop.2016.01.048

[170] Hassan, M.L., Bras, J., Hassan, E.A., Silard, C. and Mauret, E. (2014) Enzyme-Assisted Isolation of Microfibrillated Cellulose from Date Palm Fruit Stalks. Industrial Crops \& Products, 55, 102-108. http://dx.doi.org/10.1016/j.indcrop.2014.01.055

[171] Cui, S., Zhang, S., Ge, S., Xiong, L. and Sun, Q. (2016) Green Preparation and Characterization of Size-Controlled Nanocrystalline Cellulose via Ultrasonic-Assisted Enzymatic Hydrolysis. Industrial Crops \& Products, 83, 346-352. http://dx.doi.org/10.1016/j.indcrop.2016.01.019

[172] Krishnamachari, P., Hashaikeh, R., Chiesa, M. and Gad El Rab, K.R.M. (2012) Effects of Acid Hydrolysis Time on Cellulose Nanocrystals Properties: Nanoindentation and Thermogravimetric Studies. Cellulose Chemistry and Technology, 46, 13-18.

[173] Bondenson, D., Mathew, A.P. and Oskman, K. (2006) Optimization of the Isolation of Nanocrystals from Microcrystalline Cellulose by Acid Hydrolysis. Cellulose, 13, 171-180. http://dx.doi.org/10.1007/s10570-006-9061-4

[174] Qua, E.H., Hornsby, P.R., Sharma, H.S.S., Lyons, G. and Mccall, R.D. (2009) Preparation and Characterization of Poly (Vinyl Alcohol) Nanocomposites Made from Cellulose Nanofibers. Journal of Applied Polymer Science, 113, 22382247. http://dx.doi.org/10.1002/app.30116

[175] Ten, E., Turtle, J., Bahr, D., Jiang, L. and Wolcott, M. (2010) Thermal and Mechanical Properties of Poly (3-Hydroxybutyrate-Co-3-Hydroxyvalerate)/Cellulose Nanowhiskers Composites. Polymer, 51, 2652-2660. http://dx.doi.org/10.1016/j.polymer.2010.04.007

[176] Yu, H.-Y., Qin, Z.-Y. and Zhou, Z. (2011) Cellulose Nanocrystals as Green Fillers to Improve Crystallization and Hydrophilic Property of Poly (3-Hydroxybutyrate-co-3-Hydroxyvalerate). Progress in Natural Science: Materials International, 21, 478-484. http://dx.doi.org/10.1016/S1002-0071(12)60086-0

[177] Rueda, L., Saralegui, A., Fernández d'Arlas, B., Zhou, Q., Berglund, L.A., Corcuera, M.A., Mondragon, I. and Eceiza, 
A. (2013) Cellulose Nanocrystals/Polyurethane Nanocomposites. Study from the Viewpoint of Microphase Separated Structure. Carbohydrate Polymers, 92, 751-757. http://dx.doi.org/10.1016/j.carbpol.2012.09.093

[178] Cacciotti, I., Fortunati, E., Puglia, D., Kenny, J.M. and Nanni, F. (2014) Effect of Silver Nanoparticles and Cellulose Nanocrystals on Electrospun Poly (Lactic) Acid Mats: Morphology, Thermal Properties and Mechanical Behavior. Carbohydrate Polymers, 103, 22-31. http://dx.doi.org/10.1016/j.carbpol.2013.11.052

[179] Lizundia, E., Fortunati, E., Dominici, F., Vilas, J.L., León, L.M., Armentano, I., Torre, L. and Kenny, J.M. (2016) PLLA-Grafted Cellulose Nanocrystals: Role of the CNC Content and Grafting on the PLA Bionanocomposite Film Properties. Carbohydrate Polymers, 142, 105-113. http://dx.doi.org/10.1016/j.carbpol.2016.01.041

[180] Braun, B., Dorgan, J.R. and Chandler, J.P. (2008) Cellulosic Nanowhiskers. Theory and Application of Light Scattering from Polydisperse Spheroids in the Rayleigh-Gans-Debye Regime. Biomacromolecules, 9, 1255-1263. http://dx.doi.org/10.1021/bm7013137

[181] Jean, B., Dubreuil, F., Heux, L. and Cousin, F. (2008) Structural Details of Cellulose Nanocrystals/Polyelectrolytes Multilayers Probed by Neutron Reflectivity and AFM. Langmuir, 24, 3452-3458.

[182] Lizundia, E., Vilas, J.L. and Leóna, L.M. (2015) Crystallization, Structural Relaxation and Thermal Degradation in Poly (L-Lactide)/Cellulose Nanocrystal Renewable Nanocomposites. Carbohydrate Polymers, 123, 256-265. http://dx.doi.org/10.1016/j.carbpol.2015.01.054

[183] Herrera, M.A., Mathew, A.P. and Oksman, K. (2014) Gas Permeability and Selectivity of Cellulose Nanocrystals Films (Layers) Deposited by Spin Coating. Carbohydrate Polymers, 112, 494-501. http://dx.doi.org/10.1016/j.carbpol.2014.06.036

[184] Yu, H.-Y., Yang, X.-Y., Lu, F.-F., Chen, G.-Y. and Yao, J.-M. (2016) Fabrication of Multifunctional Cellulose Nanocrystals/Poly (Lactic Acid) Nanocomposites with Silver Nanoparticles by Spraying Method. Carbohydrate Polymers, 40, 209-219. http://dx.doi.org/10.1016/j.carbpol.2015.12.030

[185] Torres, F.G., Troncoso, O.P., Torres, C. and Grande, C.J. (2013) Cellulose Based Blends, Composites and Nanocomposites. In: Thomas, S., Visakh, P.M. and Mathew, A.P., Eds., Advances in Natural Polymers: Composites and Nanocomposites, Springer-Verlag Berlin Heidelberg, Heidelberg, 21-55. http://dx.doi.org/10.1007/978-3-642-20940-6 2

[186] Henriksson, M., Henriksson, G., Berglund, L.A. and Lindström, T. (2007) An Environmentally Friendly Method for Enzyme-Assisted Preparation of Microfibrillated Cellulose (MFC) Nanofibers. European Polymer Journal, 43, 34343441. http://dx.doi.org/10.1016/j.eurpolymj.2007.05.038

[187] Paakko, M., Ankerfors, M., Kosonen, H., Nykanen, A., Ahola, S., Österberg, M., Ruokolainen, J., Laine, J., Larsson, P.T., Ikkala, O. and Lindström, T. (2007) Enzymatic Hydrolysis Combined with Mechanical Shearing and High- Pressure Homogenization for Nanoscale Cellulose Fibrils and Strong Gels. Biomacromolecules, 8, 1934-1941. http://dx.doi.org/10.1021/bm061215p

[188] Janardhanan, S. and Sain, M.M. (2006) Isolation of Cellulose Microfibrils: An Enzymatic Approach. Bioresources, 1, 176-188.

[189] Tang, Y., Shen, X., Zhang, J., Guo, D., Kong, F. and Zhang, N. (2015) Extraction of Cellulose Nano-Crystals from Old Corrugated Container Fiber Using Phosphoric Acid and Enzymatic Hydrolysis Followed by Sonication. Carbohydrate Polymers, 125, 360-366. http://dx.doi.org/10.1016/j.carbpol.2015.02.063

[190] Turon, X., Rojas, O.J. and Deinhammer, R.S. (2008) Enzymatic Kinetics of Cellulose Hydrolysis: A QCM-D Study. Langmuir, 24, 3880-3887. http://dx.doi.org/10.1021/la7032753

[191] Ahola, S., Turon, X., Österberg, M., Laine, J. and Rojas, O.J. (2008) Enzymatic Hydrolysis of Native Cellulose Nanofibrils and Other Cellulose Model Films: Effect of Surface Structure. Langmuir, 24, 11592-11599. http://dx.doi.org/10.1021/la801550j

[192] Zimmermann, T., Bordeanu, N. and Strub, E. (2010) Properties of Nanofibrillated Cellulose from Different Raw Materials and Its Reinforcement Potential. Carbohydrate Polymers, 79, 1086-1093. http://dx.doi.org/10.1016/j.carbpol.2009.10.045

[193] Dufresne, A., Cavaille, J.Y. and Vignon, M.R. (1997) Mechanical Behavior of Sheets Prepared from Sugar Beet Cellulose Microfibrils. Journal of Applied Polymer Science, 64, 1185-1194. http://dx.doi.org/10.1002/(SICI)1097-4628(19970509)64:6<1185::AID-APP19>3.0.CO;2-V

[194] Spence, K.L., Venditti, R.A., Rojas, O.J., Habibi, Y. and Pawlak, J.J. (2011) A Comparative Study of Energy Consumption and Physical Properties of Microfibrillated Cellulose Produced by Different Processing Methods. Cellulose, 18, 1097-1111. http://dx.doi.org/10.1007/s10570-011-9533-Z

[195] Zhu, J.Y., Sabo, R. and Luo, X. (2011) Integrated Production of Nano-Fibrillated Cellulose and Biofuel (Ethanol) by Enzymatic Fractionation of Wood Fibers. Green Chemistry, 13, 1339-1344. http://dx.doi.org/10.1039/c1gc15103g

[196] Chakraborty, A., Sain, M. and Kortschot, M. (2005) Cellulose Microfibrils: A Novel Method of Preparation Using High Shear Refining and Cryocrushing. Holzforschung, 59, 102-107. http://dx.doi.org/10.1515/HF.2005.016 
[197] Chakraborty, A., Sain, M. and Kortschot, M. (2006) Reinforcing Potential of Wood Pulp-Derived Microfibres in a PVA Matrix. Holzforschung, 60, 53-58. http://dx.doi.org/10.1515/HF.2006.010

[198] Alemdar, A. and Sain, M. (2008) Isolation and Characterization of Nanofibers from Agricultural Residues-Wheat Straw and Soy Hulls. Bioresource Technology, 99, 1664-1671. http://dx.doi.org/10.1016/j.biortech.2007.04.029

[199] Johnson, R.K., Zink-Sharp, A., Renneckar, S.H. and Glasser, W.G. (2009) A New Bio-Based Nanocomposite: Fibrillated TEMPO-Oxidized Celluloses in Hydroxypropylcellulose Matrix. Cellulose, 16, 227-238. http://dx.doi.org/10.1007/s10570-008-9269-6

[200] Wang, S. and Cheng, Q. (2009) A Novel Process to Isolate Fibrils from Cellulose Fibers by High-Intensity Ultrasonication, Part 1: Process Optimization. Journal of Applied Polymer Science, 113, 1270-1275. http://dx.doi.org/10.1002/app.30072

[201] Tsalagkas, D., Lagaňa, R., Poljanšek, I., Oven, P. and Csoka, L. (2015) Fabrication of Bacterial Cellulose Thin Films Self-Assembled from Sonochemically Prepared Nanofibrils and Its Characterization. Ultrasonics Sonochemistry, 28, 136-143. http://dx.doi.org/10.1016/j.ultsonch.2015.07.010

[202] Ankerfors, M. (2012): Microfibrillated Cellulose: Energy-Efficient Preparation Techniques and Key Properties. Licentiate Thesis, Department of Fibre and Polymer Technology, Royal Institute of Technology, Stockholm.

[203] Frone, A.N., Panaitescu, D.M. and Donescu, D. (2011) Some Aspects Concerning the Isolation of Cellulose Microand Nano-Fibers. UPB Science Bulletin, Series B, 73, 133-152.

[204] Iwamoto, S., Nakagaito, A.N., Yano, H. and Nogi, M. (2005) Optically Transparent Composites Reinforced with Plant Fiber-Based Nanofibers. Applied Physics A: Materials Science \& Processing, 81, 1109-1112. http://dx.doi.org/10.1007/s00339-005-3316-z

[205] Ioelovich, M. and Leykin, A. (2006) Microcrystalline Cellulose: Nano-Structure Formation. Cellulose Chemistry and Technology, 40, 313-317.

[206] Cheng, Q., Wang, S.Q., Rials, T.G. and Lee, S.H. (2007) Physical and Mechanical Properties of Polyvinyl Alcohol and Polypropylene Composite Materials Reinforced with Fibril Aggregates Isolated from Regenerated Cellulose Fibres. Cellulose, 14, 593-602. http://dx.doi.org/10.1007/s10570-007-9141-0

[207]Zuluaga, R., Putaux, J.L., Restrepo, A., Mondragón, I. and Ganan, P. (2007) Cellulose Microfibrils from Banana Farming Residues: Isolation and Characterization. Cellulose, 14, 585-592. http://dx.doi.org/10.1007/s10570-007-9118-z

[208] Wågberg, L., Decher, G., Norgren, M., Lindström, T., Ankerfors, M. and Axnås, K. (2008) The Build-Up of Polyelectrolyte Multilayers of Microfibrillated Cellulose and Cationic Polyelectrolytes. Langmuir, 24, 784-795. http://dx.doi.org/10.1021/la702481v

[209] Davoudpour, Y., Hossain, S., Khalil, A., Haafiz, M., Ishak, M., Hassan, A. and Sarker, Z.I. (2015) Optimization of High Pressure Homogenization Parameters for the Isolation of Cellulosic Nanofibers Using Response Surface Methodology. Industrial Crops and Products, 74, 381-387. http://dx.doi.org/10.1016/j.indcrop.2015.05.029

[210] Tian, C., Yi, J., Wu, Y., Wu, Q., Qing, Y. and Wang, L. (2016) Preparation of Highly Charged Cellulose Nanofibrils Using High-Pressure Homogenization Coupled with Strong Acid Hydrolysis Pretreatments. Carbohydrate Polymers, 136, 485-492. http://dx.doi.org/10.1016/j.carbpol.2015.09.055

[211] Lee, S.-Y., Chun, S.-J., Kang, I.-A. and Park, J.-Y. (2009) Preparation of Cellulose Nanofibrils by High-Pressure Homogenizer and Cellulose-Based Composite Films. Journal of Industrial and Engineering Chemistry, 15, 50-55. http://dx.doi.org/10.1016/j.jiec.2008.07.008

[212] Wang, Y., Wei, X., Li, J., Wang, F., Wang, Q. and Kong, L. (2013) Homogeneous Isolation of Nanocellulose from Cotton Cellulose by High Pressure Homogenization Journal of Materials Science and Chemical Engineering, 1, 49-52.

[213] Keeratiurai, M. and Corredig, M. (2009) Effect of Dynamic High Pressure Homogenization on the Aggregation State of Soy Protein. Journal of Agricultural Food and Chemistry, 57, 3556-3562. http://dx.doi.org/10.1021/jf803562q

[214] Ferrer, A., Filpponen, I., Rodríguez, A., Laine, J. and Rojas, O.J. (2012) Valorization of Residual Empty Palm Fruit Bunch Fibers (EPFBF) by Microfluidization: Production of Nanofibrillated Cellulose and EPFBF Nanopaper. Bioresource Technology, 125, 249-255. http://dx.doi.org/10.1016/j.biortech.2012.08.108

[215] Lee, S.Y., Chun, S.J., Kang, I.A. and Park, J.Y.D. (2009) Preparation of Cellulose Nanofibers by High-Pressure Homogenizer and Cellulose-Based Composite Films. Journal of Indian Engineering Chemistry, 15, 50-55.

[216] Spence, K.L., Venditti, R.A., Rojas, O.J., Habibi, Y. and Pawlak, J.J. (2010) The Effect of Chemical Composition on Microfibrillar Cellulose Films from Wood Pulps: Water Interactions and Physical Properties for Packaging Applications. Cellulose, 17, 835-848. http://dx.doi.org/10.1007/s10570-010-9424-8

[217] Cheng, Q., Wang, S. and Rials, T.G. (2009) Poly (Vinyl Alcohol) Nanocomposites Reinforced with Cellulose Fibrils Isolated by High Intensity Ultrasonication. Composites: Part A, 40, 218-224. 
http://dx.doi.org/10.1016/j.compositesa.2008.11.009

[218] Chen, P., Yu, H., Liu, Y., Chen, W., Wang, X. and Ouyang, M. (2013) Concentration Effects on the Isolation and Dynamic Rheological Behavior of Cellulose Nanofibers via Ultrasonic Processing. Cellulose, 20, 149-157. http://dx.doi.org/10.1007/s10570-012-9829-7

[219] Wang, N., Ding, E. and Cheng, R.S. (2008) Preparation and Liquid Crystalline Properties of Spherical Cellulose Nanocrystals. Langmuir, 24, 5-8. http://dx.doi.org/10.1021/la702923w

[220] Bondeson, D., Kvien, I. and Oksman, K. (2006) Strategies for Preparation of Cellulose Whiskers from Microcrystalline Cellulose as Reinforcement in Nanocomposites. In: Oksman, K. and Sain, M., Eds., Cellulose Nanocomposites, American Chemical Society, Washington DC, 10-25. http://dx.doi.org/10.1021/bk-2006-0938.ch002

[221] Liu, C.F., Sun, R.C., Qin, M.H., Zhang, A.P., Ren, J.L., Ye, J., Luo, W. and Cao, Z.N. (2008) Succinoylation of Sugarcane Bagasse under Ultrasound Irradiation. Bioresource Technology, 99, 1465-1473. http://dx.doi.org/10.1016/j.biortech.2007.01.062

[222] Li, W., Yue, J. and Liu, S. (2012) Preparation of Nanocrystalline Cellulose via Ultrasound and Its Reinforcement Capability for Poly (Vinyl Alcohol) Composites. Ultrasonics Sonochemistry, 19, 479-485. http://dx.doi.org/10.1016/j.ultsonch.2011.11.007

[223] Nakagaito, A.N. and Yano, H. (2004) The Effect of Morphological Changes from Pulp Fiber Towards Nano-Scale Fibrillated Cellulose on the Mechanical Properties of High-Strength Plant Fiber Based Composites. Applied Physics A: Materials Science and Processing, 78, 547-552. http://dx.doi.org/10.1007/s00339-003-2453-5

[224] Zhou, Y.M., Fu, S.Y., Zheng, L.M. and Zhan, H.Y. (2012) Effect of Nanocellulose Isolation Techniques on the Formation of Reinforced Poly (Vinyl Alcohol) Nanocomposite Films. Express Polymer Letters, 6, 794-804. http://dx.doi.org/10.3144/expresspolymlett.2012.85

[225] Silvério, H.A., Flauzino Neto, W.P., Silva, I.S.V., Rosa, J.R., Pasquini, D., Assunção, R.M.N., Barud, H.S. and Ribeiro, S.J.L. (2014) Mechanical, Thermal, and Barrier Properties of Methylcellulose/Cellulose Nanocrystals Nanocomposites. Polimeros, 24, 683-688. http://dx.doi.org/10.1590/0104-1428.1691

[226] Kim, Y., Jung, R., Kim, H.S. and Jin, H.J. (2009) Transparent Nanocomposites Prepared by Incorporating Microbial Nanofibrils into Poly (L-Lactic Acid). Current Applied Physics, 9, S69-S71. http://dx.doi.org/10.1016/j.cap.2008.08.010

[227] Bhatnagar, A. and Sain, M. (2005) Processing of Cellulose Nanofiber-Reinforced Composites. Journal of Reinforced Plastics and Composites, 24, 1259-1268. http://dx.doi.org/10.1177/0731684405049864

[228] Dogan, N. and Mchugh, T.H. (2007) Effects of Microcrystalline Cellulose on Functional Properties of Hydroxy Propyl Methyl Cellulose Microcomposite Films. Journal of Food Science, 72, E16-E22. http://dx.doi.org/10.1111/j.1750-3841.2006.00237.x

[229] Freire, C.S.R., Silvestre, A.J.D., Pascoal Neto, C., Gandini, A., Martin, L. and Mondragon, I. (2008) Composites Based on Acylated Cellulose Fibers and Lowdensity Polyethylene: Effect of the Fiber Content, Degree of Substitution and Fatty Acid Chain Length on Final Properties. Composites Science and Technology, 68, 3358-3364. http://dx.doi.org/10.1016/j.compscitech.2008.09.008

[230] Wu, Q., Henriksson, M., Liu, X. and Berglund, L.A. (2007) A High Strength Nanocomposite Based on Microcrystalline Cellulose and Polyurethane. Biomacromolecules, 8, 3688-3692. http://dx.doi.org/10.1021/bm701061t

[231] Rahman, M.M., Afrin, S. and Haque, P. (2014) Characterization of Crystalline Cellulose of Jute Reinforced Poly (Vinyl Alcohol) (PVA) Biocomposite Film for Potential Biomedical Applications. Progress in Biomaterials, 3, 23-31. http://dx.doi.org/10.1007/s40204-014-0023-x

[232] Kakroodi, A.R., Cheng, S., Sain, M. and Asiri, A. (2014) Mechanical, Thermal, and Morphological Properties of Nanocomposites Based on Polyvinyl Alcohol and Cellulose Nanofiber from Aloe Vera Rind. Journal of Nanomaterials, 2014, Article ID: 903498.

[233] Zulkifli, N.I., Samat, N., Anuar, H. and Zainuddin, N. (2015) Mechanical Properties and Failure Modes of Recycled Polypropylene/Microcrystalline Cellulose Composites. Material \& Design, 69, 114-123. http://dx.doi.org/10.1016/j.matdes.2014.12.053

[234] Sonseca, A., Sahuquillo, O., Foster, E.J. and Giménez, E. (2015) Mechanical Properties and Degradation Studies of Poly (Mannitol Sebacate)/Cellulose Nanocrystals Nanocomposites. RSC Advances, 5, 55879-55891. http://dx.doi.org/10.1039/C5RA06768E

[235] Helbert, W., Cavaillé, C.Y. and Dufresne, A. (1996) Thermoplastic Nanocomposites Filled with Wheat Straw Cellulose Whiskers. Part I: Processing and Mechanical Behavior. Polymer Composites, 17, 604. http://dx.doi.org/10.1002/pc. 10650

[236] Oksman, K., Mathew, A. and Sain, M. (2006) The Effect of Morphology and Chemical Characteristics of Cellulose Reinforcements on the Crystallinity of Polylactic Acid. Journal of Applied Polymer Science, 101, 300-310. 
http://dx.doi.org/10.1002/app.23346

[237] Petersson, L., Kvien, I. and Oksman, K. (2007) Structure and Thermal Properties of Polylactic Acid/Cellulose Whiskers Nanocomposite Materials. Composites Science and Technology, 67, 2535-2544. http://dx.doi.org/10.1016/j.compscitech.2006.12.012

[238] Siqueira, G., Bras, J., Follain, N., Belbekhouche, S., Marais, S. and Dufresne, A. (2013) Thermal and Mechanical Properties of Bio-Nanocomposites Reinforced by Luffa cylindrica Cellulose Nanocrystals. Carbohydrate Polymers, 91, 711-717. http://dx.doi.org/10.1016/j.carbpol.2012.08.057

[239] Paralikar, S.A., Simonsen, J. and Lombardi, J. (2008) Poly (Vinyl Alcohol)/Cellulose Nanocrystal Barrier Membranes. Journal of Membrane Science, 320, 248-258. http://dx.doi.org/10.1016/j.memsci.2008.04.009

[240] Sanchez-Garcia, M.D., Gimenez, E. and Lagaron, J.M. (2008) Morphology and Barrier Properties of Solvent Cast Composites of Thermoplastic Biopolymers and Purified Cellulose Fibers. Carbohydrate Polymers, 71, 235-244. http://dx.doi.org/10.1016/j.carbpol.2007.05.041

[241] Svagan, A.J., Hedenqvist, M.S. and Berglund, L. (2009) Reduced Water Vapour Sorption in Cellulose Nanocomposites with Starch Matrix. Composites Science and Technology, 69, 500-506. http://dx.doi.org/10.1016/j.compscitech.2008.11.016

[242] Khan, A., Khan, R.A., Salmieria, S., Le Tiena, C., Riedl, B., Bouchard, J., Chauve, G., Tan, V., Kamal, M.R. and Lacroix, M. (2012) Mechanical and Barrier Properties of Nanocrystalline Cellulose Reinforced Chitosan Based Nanocomposite Films. Carbohydrate Polymers, 90, 1601-1608. http://dx.doi.org/10.1016/j.carbpol.2012.07.037

[243] Henriksson, M. and Berglund, L.A. (2007) Structure and Properties of Cellulose Nanocomposite Films Containing Melamine Formaldehyde. Journal of Applied Polymer Science, 106, 2817-2824. http://dx.doi.org/10.1002/app.26946

[244] Pracella, M., Haque, M.-U. and Puglia, D. (2014) Morphology and Properties Tuning of PLA/Cellulose Nanocrystals Bio-Nanocomposites by Means of Reactive Functionalization and Blending with PVAc. Polymer, 16, 3720-3728. http://dx.doi.org/10.1016/j.polymer.2014.06.071

[245] Zhang, C., Dan, Y., Peng, J., Turng, L.-S., Sabo, R. and Clemons, C. (2014) Thermal and Mechanical Properties of Natural Rubber Composites Reinforced with Cellulose Nanocrystals from Southern Pine. Advances in Polymer Technology, 33, S1.

[246] Cao, X., Dong, H. and Li, C.M. (2007) New Nanocomposite Materials Reinforced with Flax Cellulose Nanocrystals in Waterborne Polyurethane. Biomacromolecules, 8, 899-904. http://dx.doi.org/10.1021/bm0610368

[247] Gong, G., Pyo, J., Mathew, A.P. and Oksman, K. (2011) Tensile Behavior, Morphology and Viscoelastic Analysis of Cellulose Nanofiber-Reinforced (CNF) Polyvinyl Acetate (PVAc). Composites Part A: Applied Science and Manufacturing, 42, 1275-1282. http://dx.doi.org/10.1016/j.compositesa.2011.05.009

[248] Samir, M.A.S.A., Alloin, F., Sanchez, J.-Y. and Dufresne, A. (2004) Cellulose Nanocrystals Reinforced Poly (Oxyethylene). Polymer, 45, 4149-4157. http://dx.doi.org/10.1016/j.polymer.2004.03.094

[249] Jordan, J., Jacob, K.I., Tannenbaum, R., Sharaf, M.A. and Jasiuk, I. (2005) Experimental Trends in Polymer Nanocomposites: A Review. Materials Science and Engineering A, 393, 1-11. http://dx.doi.org/10.1016/j.msea.2004.09.044

[250]Zimmermann, T., Pöhler, E. and Geiger, T. (2004) Cellulose Fibrils for Polymer Reinforcement. Advanced Engineering Materials, 6, 754-761. http://dx.doi.org/10.1002/adem.200400097

[251] Shi, Q., Zhou, C., Yue, Y., Guo, W., Wu, Y. and Wu, Q. (2012) Mechanical Properties and in Vitro Degradation of Electrospun Bio-Nanocomposite Mats from PLA and Cellulose Nanocrystals. Carbohydrate Polymers, 90, 301-308. http://dx.doi.org/10.1016/j.carbpol.2012.05.042

[252] Oksman, K., Mathew, A.P., Bondeson, D. and Kvien, I. (2006) Manufacturing Process of Cellulose Whiskers/Polylactic Acid Nanocomposites. Composites Science and Technology, 66, 2776-2784. http://dx.doi.org/10.1016/j.compscitech.2006.03.002

[253] Visakh, P.M., Thomas, S., Oksman, K. and Mathew, A.P. (2012) Crosslinked Natural Rubber Nanocomposites Reinforced with Cellulose Whiskers Isolated from Bamboo Waste: Processing and Mechanical/Thermal Properties. Composites Part A: Applied Science and Manufacturing, 43, 735-741. http://dx.doi.org/10.1016/j.compositesa.2011.12.015

[254] Alemdar, A. and Sain, M. (2008) Biocomposites from Wheat Straw Nanofibers: Morphology, Thermal and Mechanical Properties. Composites Science and Technology, 68, 557-565. http://dx.doi.org/10.1016/j.compscitech.2007.05.044

[255] Mathew, A.P. and Dufresne, A. (2002) Morphological Investigation of Nanocomposites from Sorbitol Plasticized Starch and Tunicin Whiskers. Biomacromolecules, 3, 609-617. http://dx.doi.org/10.1021/bm0101769

[256] Garcia de Rodrigues, N.L., Thielemans, W. and Dufresne, A. (2006) Sisal Cellulose Whiskers Reinforce Polyvinyl Acetate Nanocomposites. Cellulose, 13, 261-270. 
[257] Choy, Y. and Simonsen, J. (2006) Cellulose Nanocrystal-Filled Carboxymethyl Cellulose Nanocomposites. Journal of Nanoscience and Nanotechnology, 6, 633-639. http://dx.doi.org/10.1166/jnn.2006.132

[258] Lu, J., Wang, T. and Drzal, L.T. (2008) Preparation and Properties of Microfibrillated Cellulose Polyvinyl Alcohol Composite Materials. Composites Part A: Applied Science and Manufacturing, 39, 738-746. http://dx.doi.org/10.1016/j.compositesa.2008.02.003

[259] Jiang, L., Morelius, E., Zhang, J., Wolcott, M. and Holbery, J. (2008) Study of the Poly (3-Hydroxybutyrate-co-3-Hydroxyvalerate)/Cellulose Nanowhisker Composites Prepared by Solution Casting and Melt Processing. Journal of Composite Materials, 42, 2629-2645. http://dx.doi.org/10.1177/0021998308096327

[260] Siqueira, G., Bras, J. and Dufresne, A. (2009) Cellulose Whiskers versus Microfibrils: Influence of the Nature of the Nanoparticle and Its Surface Functionalization on the Thermal and Mechanical Properties of Nanocomposites. Biomacromolecules, 10, 425-432. http://dx.doi.org/10.1021/bm801193d

[261] Srithep, Y., Ellingham, T., Peng, J., Sabo, R., Clemons, C., Turng, L.-S. and Pilla, S. (2013) Melt Compounding of Poly (3-Hydroxybutyrate-co-3-Hydroxyvalerate)/Nanofibrillated Cellulose Nanocomposites. Polymer Degradation and Stability, 98, 1439-1449. http://dx.doi.org/10.1016/j.polymdegradstab.2013.05.006

[262] Fortunati, E., Puglia, D., Monti, M., Santulli, C., Maniruzzaman, M. and Kenny, J.M. (2013) Cellulose Nanocrystals Extracted from Okra Fibers in PVA Nanocomposites. Journal of Applied Polymer Science, 128, 3220-3230. http://dx.doi.org/10.1002/app.38524

[263] Halász, K. and Csóka, L. (2013) Plasticized Biodegradable Poly (Lactic Acid) Based Composites Containing Cellulose in Micro- and Nanosized. Journal of Engineering, 2013, Article ID: 329379. http://dx.doi.org/10.1155/2013/329379

[264] Wang, X., Sun, H., Bai, H. and Zhang, L.-P. (2014) Thermal, Mechanical, and Degradation Properties of Nanocomposites Prepared Using Lignin-Cellulose Nanofibers and Poly (Lactic Acid). Bioresources, 9, 3211-3224. http://dx.doi.org/10.15376/biores.9.2.3211-3224

[265] Rahman, M.M., Afrin, S., Haque, P., Islam, M., Islam, M.S. and Gafur, A. (2014) Preparation and Characterization of Jute Cellulose Crystals-Reinforced Poly (Lactic Acid) Biocomposite for Biomedical Applications. International Journal of Chemical Engineering, 2014, Article ID: 842147. http://dx.doi.org/10.1155/2014/842147

[266] Mi, H.-Y., Jing, X., Peng, J., Salick, M.R., Peng, X.-F. and Turng, L.-S. (2014) Poly ( $\varepsilon$-Caprolactone) (PCL)/Cellulose Nano-Crystal (CNC) Nanocomposites and Foams. Cellulose, 21, 2727-2741. http://dx.doi.org/10.1007/s10570-014-0327-y

[267] Santos, F.A. and Tavares, M.I.B. (2014) Development and Characterization of Hybrid Materials Based on Biodegradable PLA Matrix, Microcrystalline Cellulose and Organophilic Silica. Polímeros, 24, 561-566. http://dx.doi.org/10.1590/0104-1428.1653

[268] Petersson, L. and Oksman, K. (2006) Biopolymer Based Nanocomposites: Comparing Layered Silicates and Microcrystalline Cellulose as Nanoreinforcement. Composites Science and Technology, 66, 2187-2196. http://dx.doi.org/10.1016/j.compscitech.2005.12.010

[269] Angellier, H., Molina-Boisseau, S., Lebrun, L. and Dufresne, A. (2005) Processing and Structural Properties of Waxy Maize Starch Nanocrystals Reinforced Natural Rubber. Macromolecules, 39, 3783-3792. http://dx.doi.org/10.1021/ma050054z

[270] Lagaron, J.M., Catalá, R. and Gavara, R. (2004) Structural Characteristics Defining High Barrier Polymeric Materials. Journal of Composite Materials, 20, 1-7. http://dx.doi.org/10.1179/026708304225010442

[271] Dufresne, A., Dupeyre, D. and Vignon, M.R. (2000) Cellulose Microfibrils from Potato Tuber Cells: Processing and Characterization of Starch-Cellulose Microfibril Composites. Journal of Applied Polymer Science, 76, 2080-2092. http://dx.doi.org/10.1002/(SICI)1097-4628(20000628)76:14<2080::AID-APP12>3.0.CO;2-U

[272] Lu, Y., Weng, L. and Cao, X. (2005) Biocomposites of Plasticized Starch Reinforced with Cellulose Crystallites from Cottonseed Linter. Macromolecular Bioscience, 5, 1101-1107. http://dx.doi.org/10.1002/mabi.200500094

[273] Plackett, D., Anturi, H., Hedenqvist, M., Ankerfors, M., Gallstedt, M., Lindstrom, T. and Siró, I. (2010) Physical Properties and Morphology of Films Prepared from Microfibrillated Cellulose and Microfibrillated Cellulose in Combination with Amylopectin. Journal of Applied Polymer Science, 117, 3601-3609.

[274] Lange, J. and Wyser, Y. (2004) Recent Innovations in Barrier Technologies for Plastic Packaging: A Review. Packaging Technology and Science, 16, 149-158. http://dx.doi.org/10.1002/pts.621

[275] Bondeson, D. and Oksman, K. (2007) Polylactic Acid/Cellulose Whisker Nanocomposites Modified by Polyvinyl Alcohol. Composites Part A: Applied Science and Manufacturing, 38, 2486-2492. http://dx.doi.org/10.1016/j.compositesa.2007.08.001

[276] Mohanty, A.K., Misra, M. and Drzal, L.T. (2001) Surface Modifications of Natural Fibers and Performance of the Resulting Biocomposites: An Overview. Composite Interfaces, 8, 313-342. http://dx.doi.org/10.1163/156855401753255422 
[277] Raquez, J.-M., Murema, Y., Goffin, A.-L., Habibi, Y., Ruelle, B., Debuyl, F. and Dubois, P. (2012) Surface-Modification of Cellulose Nanowhiskers and Their Use as Nanoreinforcers into Polylactide: A Sustainably-Integrated Approach. Composites Science and Technology, 72, 544-549. http://dx.doi.org/10.1016/j.compscitech.2011.11.017

[278] Ljungberg, N., Bonini, C., Bortolussi, F., Boisson, C., Heux, L. and Cavaille, J.Y. (2005) New Nanocomposite Materials Reinforced with Cellulose Whiskers in Atactic Polypropylene: Effect of Surface and Dispersion Characteristics. Biomacromolecules, 6, 2732-2739. http://dx.doi.org/10.1021/bm050222v

[279] Peng, B., Han, X., Liu, H., Berry, R.C. and Tam, K.C. (2013) Interactions between Surfactants and Polymer-Grafted Nanocrystalline Celulose. Colloids and Surfaces A: Physicochemical and Engineering Aspects, 421, 142-149. http://dx.doi.org/10.1016/j.colsurfa.2012.12.059

[280] Emami, Z., Meng, Q., Pircheraghi, G. and Manas-Zloczower, I. (2015) Use of Surfactants in Cellulose Nanowhisker/Epoxy Nanocomposites: Effect on Filler Dispersion and System Properties. Cellulose, 22, 3161-3176. http://dx.doi.org/10.1007/s10570-015-0728-6

[281] Goffin, A.-L., Raquez, J.-M., Duquesne, E., Siqueira, G., Habibi, Y., Dufresne, A. and Dubois, P.H. (2011) Poly (عCaprolactone) Based Nanocomposites Reinforced by Surface-Grafted Cellulose Nanowhiskers via Extrusion Processing: Morphology, Rheology, and Thermo-Mechanical Properties. Polymer, 52, 1532-1538. http://dx.doi.org/10.1016/j.polymer.2011.02.004

[282] Yu, H.-Y. and Qin, Z.-Y. (2014) Surface Grafting of Cellulose Nanocrystals with Poly (3-Hydroxybutyrate-Co-3-Hydroxyvalerate). Carbohydrate Polymers, 101, 471-478. http://dx.doi.org/10.1016/j.carbpol.2013.09.048

[283] Bunsomsit, K., Magaraphan, K., O'rear, E.A. and Grady, B.P. (2002) Polypyrrole-Coated Natural Rubber Latex by Admicellar Polymerization. Colloid and Polymer Science, 280, 509-516. http://dx.doi.org/10.1007/s00396-001-0639-y

[284] Lekpittaya, P., Yanumet, N., Grady, B.P. and O'rear, E.A. (2004) Resistivity of Conductive Polymer-Coated Fabric. Journal of Applied Polymer Science, 92, 2629-2636. http://dx.doi.org/10.1002/app.20270

[285] Tragoonwichian, S., O'rear, E.A. and Yanumet, N. (2008) Admicellar Polymerization of 2-Hydroxy-4-Acryloyloxybenzophenone: The Production of UV-Protective Cotton. Colloids and Surfaces A: Physicochemical and Engineering Aspects, 329, 87-94. http://dx.doi.org/10.1016/j.colsurfa.2008.06.051

[286] Sangthong, S., Pongprayoon, T. and Yanumet, N. (2009) Mechanical Property Improvement of Unsaturated Polyester Composite Reinforced with Admicellar-Treated Sisal Fibers. Composites Part A: Applied Science and Manufacturing, 40, 678-694. http://dx.doi.org/10.1016/j.compositesa.2008.12.004

[287] Hanumansetty, S., Maity, J., Foster, R. and O'Rear, E.A. (2012) Stain Resistance of Cotton Fabrics before and after Finishing with Admicellar Polymerization. Applied Sciences, 2, 192-200. http://dx.doi.org/10.3390/app2010192

[288] Pongprayoon, T., Yanumet, N. and Sangthong, S. (2008) Surface Behavior and Film Formation Analysis of Sisal Fiber Coated by Poly (Methyl Methacrylate) Ultrathin Film. Colloids and Surfaces A: Physicochemical and Engineering Aspects, 320, 130-137. http://dx.doi.org/10.1016/j.colsurfa.2008.01.050

[289] Boufi, S. and Gandini, A. (2001) Formation of Polymeric Films on Cellulosic Surfaces by Admicellar Polymerization. Cellulose, 8, 303-312. http://dx.doi.org/10.1023/A:1015137116216

[290] Yaun, W.L., O'rear, E.A., Grady, B.P. and Glatzhofer, D.T. (2002) Nanometer-Thick Poly (Pyrrole) Films Formed by Admicellar Polymerization under Conditions of Depleting Adsolubilization. Langmuir, 18, 3343-3351. http://dx.doi.org/10.1021/la011349i

[291] Lai, C.L., Harwell, J.H., O’rear, E.A., komotsuzaki, S., Arai, J., Nakakawaii, T. and Ito, Y. (1995) Formation of Poly (Tetrafluoroethylene) Thin Films on Alumina by Admicelar Polymerization. Langmuir, 11, 905-911. http://dx.doi.org/10.1021/la00003a038

[292] Oksman, K., Jonoobi, M., Hietala, M. and Vargas, N.H. (2013) Cellulose Nanocomposites Processing Using Extrusion. In: Postek, M.T., Moon, R.J., Rudie, A. and Bilodeau, M., Eds., Production and Applications of Cellulose Nanomaterials, TAPPI Press, Atlanta, 99-102.

[293] Rojas, O.J., Montero, G.A. and Habibi, Y. (2009) Electrospun Nanocomposites from Polystyrene Loaded with Cellulose Nanowhiskers. Journal of Applied Polymer Science, 113, 927-935. http://dx.doi.org/10.1002/app.30011

[294] Magalhaes, W.L.E., Cao, X.D. and Lucia, L.A. (2009) Cellulose Nanocrystals/Cellulose Core-In-Shell Nanocomposite Assemblies. Langmuir, 25, 13250-13257. http://dx.doi.org/10.1021/la901928j

[295] Lu, P. and Hsieh, Y.L. (2009) Cellulose Nanocrystal-Filled Poly (Acrylic Acid) Nanocomposite Fibrous Membranes. Nanotechnology, 20, Article ID: 415604. http://dx.doi.org/10.1088/0957-4484/20/41/415604

[296] Peresin, M., Youssef, H., Zoppe, J., Pawlak, J.J. and Orlando, R. (2010) Nanofiber Composites of Polyvinyl Alcohol and Cellulose Nanocrystals: Manufacture and Characterization. Biomacromolecules, 11, 674-681. http://dx.doi.org/10.1021/bm901254n

[297] Olsson, R.T., Kraemer, R., Lopez-Rubio, A., Torres-Giner, S., Ocio, M.J. and Lagaron, J.M. (2010) Extraction of Mi- 
crofibrils from Bacterial Cellulose Networks for Electrospinning of Anisotropic Biohybrid Fiber Yarns. Macromolecules, 43, 4201-4209. http://dx.doi.org/10.1021/ma100217q

[298] Zoppe, O., Habibi, Y., Rojas, O.J., Venditti, R.A., Johansson, L.-S., Efimenko, K., Osterberg, M. and Laine, J. (2011) Poly (N-Isopropylacrylamide) Brushes Grafted from Cellulose Nanocrystals via Surface-Initiated Single-Electron Transfer Living Radical Polymerization. Biomacromolecules, 11, 2683-2691. http://dx.doi.org/10.1021/bm100719d

[299] Malainine, M.E., Mahrouz, M. and Dufresne, A. (2005) Thermoplastic Nanocomposites Based on Cellulose Microfibrils from Opuntia Ficus-Indica Parenchyma Cell. Composites Science and Technology, 65, 1520-1526. http://dx.doi.org/10.1016/j.compscitech.2005.01.003

[300] Orts, W.J., Shey, J., Imam, S.H., Glenn, G.M., Guttman, M.E. and Revol, J.F. (2005) Application of Cellulose Microfibrils in Polymer Nanocomposites. Journal of Polymers and the Environment, 13, 301-306. http://dx.doi.org/10.1007/s10924-005-5514-3

[301] Roman, M. and Winter, W.T. (2006) Cellulose Nanocrystals for Thermoplastic Reinforcement: Effect of Filler Surface Chemistry on Composite Properties. In: Oksman, K. and Sain, M., EdS., Cellulose Nanocomposites. Processing Characterization, and Properties, ACS Symposium Series, Washington DC, 99-113. http://dx.doi.org/10.1021/bk-2006-0938.ch008

[302] Samir, M.A.S.A., Alloin, F., Sanchez, J.-Y. and Dufresne, A. (2004) Crosslinked Nanocomposite Polymer Electrolytes Reinforced with Cellulose Whiskers. Macromolecules, 37, 4839-4844. http://dx.doi.org/10.1021/ma049504y

[303] Dufresne, A. (2010) Processing of Polymer Nanocomposites Reinforced with Polysaccharide Nanocrystals. Molecules, 15, 4111-4128. http://dx.doi.org/10.3390/molecules15064111

[304] Yousefi, H., Faezipour, M., Nishino, T., Shakeri, A. and Ebrahimi, G.(2011) All-Cellulose Composite and Nanocomposite Made from Partially Dissolved Micro- and Nanofibers of Canola Straw. Polymer Journal, 43, 559-564. http://dx.doi.org/10.1038/pj.2011.31

[305] Nishino, T., Matsuda, I. and Hirao, K. (2004) All-Cellulose Composite. Macromolecules, 37, 7683-7687. http://dx.doi.org/10.1021/ma049300h

[306] Soykeabkaew, N., Arimoto, N., Nishino, T. and Peijs, T. (2008) All-Cellulose Composites by Surface Selective Dissolution of Aligned Ligno-Cellulosic Fibres. Composites Science and Technology, 68, 2201-2207. http://dx.doi.org/10.1016/j.compscitech.2008.03.023

[307] Gindl, W. and Keckes, J. (2005) All-Cellulose Nanocomposite. Polymer, 46, 10221-10225. http://dx.doi.org/10.1016/j.polymer.2005.08.040

[308] Nishino, T. and Arimoto, N. (2007) All-Cellulose Composite by Selective Dissolving of Fiber Surface. Biomacromolecules, 8, 2712-2716. http://dx.doi.org/10.1021/bm0703416

[309] Duchemin, B.J.C., Mathew, A. and Oksman, K. (2009) All-Cellulose Composites by Partial Dissolution in the Ionic Liquid 1-Butyl-3-Methylimidazolium Chloride. Composites, 40, 2031-2037. http://dx.doi.org/10.1016/j.compositesa.2009.09.013

[310] Soykeabkaew, N., Chandeep, S., Nishino, T. and Peijs, T. (2009) All-Cellulose Nanocomposites by Surface Selective Dissolution of Bacterial Cellulose. Cellulose, 16, 435-444. http://dx.doi.org/10.1007/s10570-009-9285-1

[311] Qi, H., Cai, J., Zhang, L. and Kuga, S. (2009) Properties of Films Composed of Cellulose Nanowhiskers and a Cellulose Matrix Regenerated from Alkali/Urea Solution. Biomacromolecules, 10, 1597-1602. http://dx.doi.org/10.1021/bm9001975

[312] Gindl, W., Schoberl, T. and Keckes, J. (2006) Structure and Properties of a Pulp Fibre-Reinforced Composite with Regenerated Cellulose Matrix. Applied Physics A, 83, 19-22. http://dx.doi.org/10.1007/s00339-005-3451-6

[313] Chazeau, L., Cavaille, J.Y., Canova, G., Dendievel, R. and Boutherin, B. (1999) Viscoelastic Properties of Plasticized PVC Reinforced with Cellulose Whiskers. Journal of Applied Polymer Science, 71, 1797-1808. http://dx.doi.org/10.1002/(SICI)1097-4628(19990314)71:11<1797::AID-APP9>3.0.CO;2-E

[314] Qiu, W.L., Endo, T. and Hirotsu, T. (2004) Interfacial Interactions of a Novel Mechanochemical Composite of Cellulose with Maleated Polypropylene. Journal Applied Polymer Science, 94, 1326-1335. http://dx.doi.org/10.1002/app.21123

[315] Chauve, G., Heux, L., Arouini, R. and Mazeau, K. (2005) Cellulose Poly (Ethylene-Covinyl Acetate) Nanocomposites Studied by Molecular Modeling and Mechanical Spectroscopy. Biomacromolecules, 6, 2025-2031. http://dx.doi.org/10.1021/bm0501205

[316] Kuan, C.F., Ma, C.C.M., Hsu-Chiang, K.A., Wu, H.L. and Liao, Y.M. (2006) Preparation and Characterization of the Novel Water-Cross Linked Cellulose Reinforced Poly (Butylene Succinate) Composites. Composites Science Technology, 66, 2231-2241. http://dx.doi.org/10.1016/j.compscitech.2005.12.011

[317] Bondeson, D. and Oksman, K. (2007) Dispersion and Characteristics of Surfactant Modified Cellulose Whiskers Na- 
nocomposites. Composite Interfaces, 14, 617-630. http://dx.doi.org/10.1163/156855407782106519

[318] Soulestin, J., Quievy, N., Sclavons, M. and Devaux, J. (2007) Polyolefins-Biofibre Composites: A New Way for an Industrial Production. Polymer Engineering \& Science, 47, 467-476. http://dx.doi.org/10.1002/pen.20706

[319] Abdul Khalil, H.P.S., Bhat, A.H., Abu Bakar, A., Tahir, P.Md., Zaidul, I.S.M. and Jawaid, M. (2014) Cellulosic Nanocomposites from Natural Fibers for Medical Applications: A Review. In: Pandey, J.K., Takagi, H., Nakagaito, A.N. and Kim, H.-J., Eds., Handbook of Polymer Nanocomposites. Processing, Performance and Application, Vol. C: Polymer Nanocomposites of Cellulose Nanoparticles, Springer Berlin Heidelberg, Heidelberg, 475-511.

[320] Hajji, P., Cavaille, J.Y., Favier, V., Gauthier, C. and Vigier, G. (1996) Tensile Behavior of Nanocomposites from Latex and Cellulose Whiskers. Polymer Composites, 17, 612-619.

[321] Pereda, M., Kissi, N.E. and Dufresne, A. (2014) Extrusion of Polysaccharide Nanocrystal Reinforced Polymer Nanocomposites through Compatibilization with Poly (Ethylene Oxide). ACS Applied Materials \& Interfaces, 6, 9365-9375. http://dx.doi.org/10.1021/am501755p

[322] Takamura, M., Nakamura, T., Takahashi, T. and Koyama, K. (2008) Effect of Type of Peroxide on Cross-Linking of Poly (L-Lactide). Polymer Degradation and Stability, 93, 1909-1916. http://dx.doi.org/10.1016/j.polymdegradstab.2008.07.001

[323] Ma, P., Cai, X., Zhang, Y., Wang, S., Dong, W., Chen, M. and Lemstra, P.J. (2014) In-Situ Compatibilization of Poly (Lactic Acid) and Poly (Butylene Adipate-Co-Terephthalate) Blends by Using Dicumyl Peroxide as a Free-Radical Initiator. Polymer Degradation and Stability, 102, 145-151. http://dx.doi.org/10.1016/i.polymdegradstab.2014.01.025

[324] Wei, L., McDonald, A.G. and Stark, N.M. (2015) Grafting of Bacterial Polyhydroxybutyrate (PHB) onto Cellulose via in Situ Reactive Extrusion with Dicumyl Peroxide. Biomacromolecules, 16, 1040-1049.

[325] Dhar, P., Tarafder, D., Kumar, A. and Katiyar, V. (2016) Thermally Recyclable Polylactic Acid/Cellulose Nanocrystal Films through Reactive Extrusion Process. Polymer, 87, 268-282. http://dx.doi.org/10.1016/j.polymer.2016.02.004

[326] Frenot, A. and Chronakis, I.S. (2003) Polymer Nanofibers Assembled by Electrospinning. Current Opinion in Colloid and Interface Science, 8, 64-75. http://dx.doi.org/10.1016/S1359-0294(03)00004-9

[327] Park, I., Kang, M., Kim, H.S. and Jin, H.J. (2007) Electrospinning of Poly (Ethylene Oxide) with Bacterial Cellulose Whiskers. Macromolecular Symposia, 249, 289-294. http://dx.doi.org/10.1002/masy.200750347

[328] Zoppe, J.O., Peresin, M.S., Habibi, Y., Venditti, R.A. and Rojas, O.J. (2009) Reinforcing Poly ( $\varepsilon$-Caprolactone) Nanofibers with Cellulose Nanocrystals. ACS Applied Materials \& Interfaces, 1, 1996-2004. http://dx.doi.org/10.1021/am9003705

[329] Favier, V., Canova, G.R., Cavaille, J.Y., Chanzy, H., Dufresne, A. and Gauthier, C. (1995) Nanocomposite Materials from Latex and Cellulose Whiskers. Polymers Advanced Technologies, 6, 351-355. http://dx.doi.org/10.1002/pat.1995.220060514

[330] Samir, M.A.S.A, Alloin, F., Gorecki, W., Sanchez, J.-Y. and Dufresne, A. (2004) Nanocomposite Polymer Electrolytes Based on Poly-(Oxyethylene) and Cellulose Nanocrystals. The Journal of Physical Chemistry B, 108, 10845-10852. http://dx.doi.org/10.1021/jp0494483

[331] Samir, M.A.S.A., Montero Mateos, A., Alloin, F., Sanchez, J.-Y. and Dufresne, A. (2004) Plasticized Nanocomposite Polymer Electrolytes Based on Poly (Oxyethylene) and Cellulose Whiskers. Electrochemica Acta, 49, 4667-4677. http://dx.doi.org/10.1016/j.electacta.2004.05.021

[332] Dong, S. and Roman, M. (2007) Fluorescently Labeled Cellulose Nanocrystals for Bioimaging Applications. Journal of the American Chemical Society, 129, 13810-13811. http://dx.doi.org/10.1021/ja0761961

[333] Bodin, A., Backdahl, H. and Gatrnholm, P. (2007) Nano Cellulose as a Scaffold for Tissue Engineered Blood Vessels. Tissue Engineering, 13, 885 .

[334] Liang, D., Hsiao, B.S. and Chu, B. (2007) Functional Electrospun Nanofibrous Scaffolds for Biomedical Applications. Advanced Drug Delivery Reviews, 59, 1392-1412. http://dx.doi.org/10.1016/j.addr.2007.04.021

[335] Wan, Z., Huang, Y., Yuan, C.D., Raman, S., Zhu, Y., Jiang, H.J., He, F. and Gao, C. (2007) Biomimetic Synthesis of Hydroxyapatite/Bacterial Cellulose Nanocomposites. Materials Science and Engineering, 27, 855-864. http://dx.doi.org/10.1016/j.msec.2006.10.002

[336] Barbanti, S.H., Zavaglia, C.A.C. and Duek, E.A.R. (2005) Polímeros Bioreabsorvíveis na Engenharia de Tecidos. Polimeros: Ciência e Tecnologia, 15, 13-21. http://dx.doi.org/10.1590/S0104-14282005000100006

[337] Pooyan, P., Tannenbaum, R. and Garmestani, H. (2012) Mechanical Behavior of a Cellulose-Reinforced Scaffold in Vascular Tissue Engineering. Journal of the Mechanical Behavior of Biomedical Materials, 7, 50-59. http://dx.doi.org/10.1016/j.jmbbm.2011.09.009

[338] Saska, S., Barud, H.S., Gaspar, A.M.M., Marchetto, R., Ribeiro, S.J.L. and Messaddeq, Y. (2011) Bacterial Cellulose-Hydroxyapatite Nanocomposites for Bone Regeneration. International Journal of Biomaterials, 2011, 1-8. 
http://dx.doi.org/10.1155/2011/175362

[339] Cherian, B.M., Leão, A.L., Souza, S.F., Costa, L.M.M., Olyveira, G.M., Kottaisamy, M., Nagarajan, E.R. and Thomas, S. (2011) Cellulose Nanocomposites with Nanofibres Isolated from Pineapple Leaf Fibers for Medical Applications. Carbohydrate Polymers, 86, 1790-1798. http://dx.doi.org/10.1016/j.carbpol.2011.07.009 